NBSIR 88-3781

\title{
Recommended Procedure for Rating and Testing of Variable Speed Air Source Unitary Air Conditioners and Heat Pumps
}

Piotr A. Domanski

U.S. DEPARTMENT OF COMMERCE

National Bureau of Standards

National Engineering Laboratory

Center for Building Technology

Building Environment Division

Gaithersburg, MD 20899

May 1988

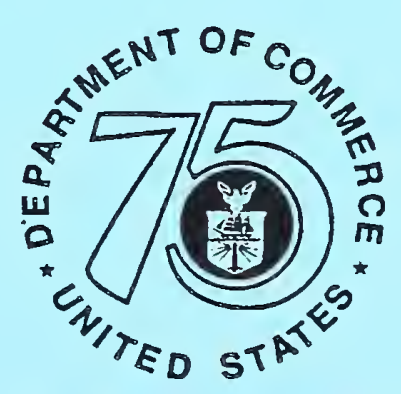

75 Years SUlmulating America's Progress

Sponsored by:

U.S. Department of Energy

Washington, DC 20585 

NBSIR 88-3781

RECOMMENDED PROCEDURE FOR

RATING AND TESTING OF VARIABLE

SPEED AIR SOURCE UNITARY AIR

CONDITIONERS AND HEAT PUMPS

Piotr A. Domanski

U.S. DEPARTMENT OF COMMERCE

National Bureau of Standards

National Engineering Laboratory

Center For Building Technology

Building Environment Division

Gaithersburg, MD 20899

May 1988

Sponsored by::

U.S. Department of Energy

Washington, DC 20585

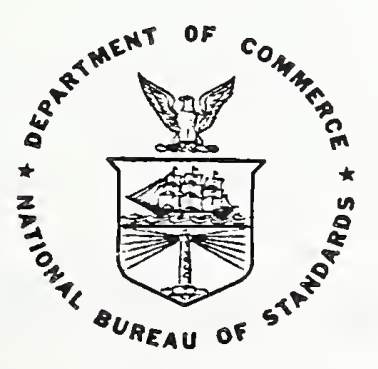

U.S. DEPARTMENT OF COMMERCE, C. William Verity, Secretary

NATIONAL BUREAU OF STANDARDS, Ernest Ambler, Director 

RECOMMENDED PROCEDURE FOR RATING AND TESTING OF

VARIABLE SPEED AIR SOURCE UNITARY AIR CONDITIONERS AND HEAT PUMPS

Abstract

A procedure is presented for testing and rating variable speed, residential air conditioners and heat pumps. The procedure is derived in part from existing procedures for single speed and two speed systems. The main addition to the existing procedures is a new algorithm for representation of variable speed unit performance in the intermediate speed operation range. Analysis and background which led to the formulation of the procedure are included as well as calculation examples for the cooling and heating mode. This procedure has been prepared for the Department of Energy for consideration in the rule making process.

Key Words: Air conditioner, heat pump, rating procedure, seasonal performance, variable speed system. 


\section{DISCLAIMER}

In view of the presently accepted practice of the building industry in the United States, common U.S. units of measurement are used in this report. In recognition of the United States as a signatory to the General Conference of Weights and Measures, which gave official status to the SI system of units in 1960, appropriate conversion factors are provided in the table below. The reader interested in making further use of the coherent system of SI units is referred to: NBS SP330, 1972 Edition, "The International System of Units," or E380-72, ASTM Metric Practice Guide (American National Standard 2210.1)。

\section{METRIC CONVERSION FACTORS}

$\begin{array}{ll}\text { Length } & \begin{array}{l}1 \text { inch (in) }=25.4 \text { millimeters (mm) } \\ 1 \text { foot }(\mathrm{ft})=0.3048 \text { meter }(\mathrm{m})\end{array} \\ \text { Area } & 1 \mathrm{ft}^{2}=0.092903 \mathrm{~m}^{2} \\ \text { Volume } & 1 \mathrm{ft}^{3}=0.028317 \mathrm{~m}^{3} \\ \text { Temperature } & { }^{\circ} \mathrm{F}=9 / 5^{\circ} \mathrm{C}+32 \\ \begin{array}{l}\text { Temperature } \\ \text { Interval }\end{array} & 1^{\circ} \mathrm{F}=5 / 9^{\circ} \mathrm{C} \text { or } \mathrm{K} \\ \text { Mass } & 1 \mathrm{pound}(1 \mathrm{~b})=0.453592 \mathrm{kilogram}(\mathrm{kg}) \\ \text { Mass Per Unit } & 1 \mathrm{lb} / \mathrm{ft}{ }^{3}=16.0185 \mathrm{~kg} / \mathrm{m}^{3} \\ \text { Volume } & 1 \mathrm{Btu}=1.05506 \mathrm{kilojoules}(\mathrm{kJ}) \\ \text { Energy } & 1 \mathrm{Btu} /\left[1 \mathrm{~b} \circ{ }^{\circ} \mathrm{F}\right]=4.1868 \mathrm{~kJ} /[\mathrm{kg} \cdot \mathrm{K}] \\ \text { Specific Heat } & 1 \mathrm{gallon}=0.0037854 \mathrm{~m}^{3} \\ \text { Gallon } & \end{array}$


TABLE OF CONTENTS

ABSTRACT

DISCLAIMER

TABLE OF CONTENTS. . . . . . . . . . . . . . . . . . . . . . iv

LIST OF FIGURES. . . . . . . . . . . . . . . . . . . . . . . . . . vi

LIST OF TABLES . . . . . . . . . . . . . . . . . . . . . vii

LIST OF SYMBOLS. . . . . . . . . . . . . . . . . . . . . viii

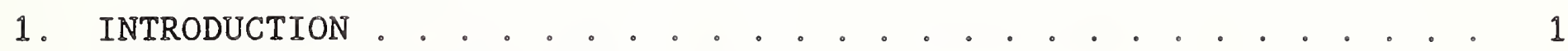

2. BACKGROUND OF THE PROCEDURE DEVELOPMENT. . . . . . . . . . . . . . 4

2.1 Intermediate Speed Test . . . . . . . . . . . . . . 4

2.2 Interpolation of the Intermediate Speed Power Input . . . . . 8

2.3 Cyclic Test . . . . . . . . . . . . . . . . . . 12

2.4 Capacity and Power Input Lines at the Maximum Compressor

Speed in the Heating Mode . . . . . . . . . . . . . . . . . . 17

2.5 Building Load in the Heating Mode . . . . . . . . . . . . . . 19

2.6 Measurement of the Electrical Energy Input. . . . . . . . . . 21

2.7 Needed Research . . . . . . . . . . . . . . . . . 23

3. RATING PROCEDURE FOR VARIABLE SPEED SYSTEMS IN THE COOLING MODE

3.1 Requirements for Testing Conditions and Testing Procedures . . 25

3.1.1 Tests and Testing Conditions . . . . . . . . . . . . 25

3.1.2 Cyclic Test. . . . . . . . . . . . . . . . 25

3.1.3 Intermediate Speed Test. . . . . . . . . . . . . 27

3.1.4 Air Quantity Measurement . . . . . . . . . . . . 27

3.1 .5 Power Measurement. . . . . . . . . . . . . . . . 28

3.2 Calculation of Seasonal Energy Efficiency Ratio, SEER . . . . 28

4. RATING PROCEDURE FOR VARIABLE SPEED SYSTEMS IN THE HEATING MODE

4.1 Requirements for Testing Conditions and Testing Procedures. . 36

4.1.1 Tests and Testing Conditions . . . . . . . . . . . . 36

4.1.2 Cyclic Test. . . . . . . . . . . . . . . . . 36

4.1.3 Intermediate Speed Frost Accumulation Test . . . . . 37

4.1.4 Maximum Speed Frost Accumulation Test. . . . . . . . . 37

4.1.5 Nominal Speed High Temperature Test. . . . . . . . . . 37

4.1.6 Air Quantity Measurement . . . . . . . . . . . . 38

4.1.7 Power Measurement. . . . . . . . . . . . . . . . 38

4.2 Calculation of Heating Seasonal Performance Factor, HSPF. . . 38 
5. REFERENCES . . . . . . . . . . . . . . . . . . . . 49

APPENDIX A. EXAMPLE OF SEER CALCULATIONS . . . . . . . . . . . . . 51

APPENDIX B. EXAMPLE OF HSPF CALCULATIONS . . . . . . . . . . . . . . 56 


\section{LIST OF FIGURES}

1. Building cooling load and capacity of variable speed air-conditioner

2. System power at intermediate speed operation using different interpolations. . . . . . . . . . . . . . . . . . . . 5

3. System EER at intermediate speed operation using different interpolations. . . . . . . . . . . . . . . . . . 10

4. Cyclic rate for a single speed system and a variable speed system. . . . . . . . . . . . . . . . . . 14

5. Maximum theoretical SEER penalty at default Cd. . . . . . . 16

6. Ratio of measured capacity to linearly interpolated capacity (using $17^{\circ} \mathrm{F}$ and $47^{\circ} \mathrm{F}$ data) for the frost accumulation test . . . . . . . . . . . . . 19

7. Ratio of measured power to linearly interpolated power (using $17^{\circ} \mathrm{F}$ and $47^{\circ} \mathrm{F}$ data) for the frost accumulation test.

8. Ratio of measured COP to linearly interpolated COP

(using $17^{\circ} \mathrm{F}$ and $47^{\circ} \mathrm{F}$ data) for the frost accumulation test.

9. Deformation of the current waveform at input to a three phase inverter at $30 \mathrm{~Hz}$ output frequency . . . . . . . . 22

10. Building heating load and capacity of a variable speed heat pump. . . . . . . . . . . . . . . . 42

11. Heating climatic regions and distributions of heating load hours (HLH) for the United States. . . . . . . .68 
1. Summary of Test Conditions for Rating Variable Speed Systems in the Cooling Mode... . . . . . . . . . . . . . . 61

2. Distribution of Fractional Cooling Hours in Temperature Bins for Calculation of SEER . . . . . . . . . . . . . . 62

3. Summary of Test Conditions for Rating Variable Speed Systems in the Heating Mode . . . . . . . . . . . . . . . . 63

4. Distribution of Fractional Heating Hours in Temperature Bins, Heating Load Hours and Outdoor Design Temperature for Different Climatic Regions. . . . . . . . . . . . . . 64

5. Standard Design Heating Requirements. . . . . . . . . . . . 65

Al. Bin Calculation Worksheet for Evaluation of SEER. . . . . . . . 66

B1. Bin Calculation Worksheet for Evaluation of HSPF. . . . . . . 67 


\section{LIST OF SYMBOLS}

\begin{tabular}{|c|c|c|}
\hline$A_{9}^{k}=2$ & $=$ & $\begin{array}{l}\text { steady state test in the cooling mode at conditions } \\
\text { specified in Table } 1\end{array}$ \\
\hline a & $=$ & coefficienț used in eq. (3.17) and eq. (4.19), (-) \\
\hline$B L(t)$ & $=$ & building load at outdoor temperature $t,(B t u / h)$ \\
\hline $\mathrm{B}_{82}^{\mathrm{k}}=1$ & $=$ & $\begin{array}{l}\text { steady state test in the cooling mode at conditions specified } \\
\text { in Table } 1\end{array}$ \\
\hline$B_{8}^{k}=2$ & $=$ & $\begin{array}{l}\text { steady state test in the cooling mode at conditions specified } \\
\text { in Table } 1\end{array}$ \\
\hline$B_{67}^{k}=1$ & $=$ & $\begin{array}{l}\text { steady state test in the cooling mode at conditions specified } \\
\text { in Table } 1\end{array}$ \\
\hline$b$ & $=$ & coefficient used in eq. (3.17) and eq. (4.19), (-) \\
\hline C & $=$ & $\begin{array}{l}0.77 \text {, an experience factor which improves the agreement } \\
\text { between calculated and measured building loads, (-) }\end{array}$ \\
\hline$C_{D}$ & $=$ & cyclic degradation coefficient of performance, \\
\hline CFM & $=$ & volumetric. flow rate of air, $\left(\mathrm{ft}^{3} / \mathrm{min}\right)$ \\
\hline COP & $=$ & coefficient of performance, $(-)$ \\
\hline$C_{67}^{k}=1$ & $=$ & $\begin{array}{l}\text { cyclic test in the cooling mode at conditions specified in } \\
\text { Table } 1\end{array}$ \\
\hline c & $=$ & coefficient used in eq. (3.17) and eq. (4.19), \\
\hline DHR & $=$ & design heating requirement, $(B t u / h)$ \\
\hline$D_{67}^{k}=1$ & $=$ & $\begin{array}{l}\text { cyclic test in the cooling mode at conditions specified in } \\
\text { Table } 1\end{array}$ \\
\hline$E(t)$ & $=$ & $\begin{array}{l}\text { power input to a system at outdoor temperature } t \text { during } \\
\text { steady state operation, different subscripts may be used, (W) }\end{array}$ \\
\hline EER & $=$ & energy efficiency ratio, $(B t u / W \cdot h)$ \\
\hline$e\left(t_{j}\right)$ & $=$ & power usage in bin temperature $t_{j}$, (W) \\
\hline HSPF & $=$ & heating seasonal performance factor, $(B t u / W \cdot h)$ \\
\hline$I_{87}^{k}=i$ & $=$ & $\begin{array}{l}\text { intermediate speed test in the cooling mode at conditions } \\
\text { specified in Table } 1\end{array}$ \\
\hline j & $=$ & sequential number of a temperature bin, \\
\hline
\end{tabular}




\begin{tabular}{|c|c|c|}
\hline $\mathrm{n}_{\mathrm{j}}$ & $=$ & fractional bin hours in bin $j$, per Table 2 or Table 3 , (-) \\
\hline $\mathrm{n}_{\mathrm{s}}$ & $=$ & cycling rate of a single speed system, $(1 / \mathrm{h})$ \\
\hline $\mathrm{n}_{\mathrm{v}}$ & $=$ & cycling rate of a variable speed system, $(1 / \mathrm{h})$ \\
\hline PLF & $=$ & part load factor, $(-)$ \\
\hline$Q(t)$ & $=$ & $\begin{array}{l}\text { steady state capacity at outdoor temperature } t \text {, different } \\
\text { subscripts and superscripts may be used, (Btu/h) }\end{array}$ \\
\hline$q\left(t_{j}\right)$ & $=$ & cooling done in bin temperature $t_{\jmath},(B t u / h)$ \\
\hline $\mathrm{RH}\left(t_{j}\right)$ & $=$ & $\begin{array}{l}\text { power input to the supplementary resistant heater required } \\
\text { in those cases when the heat pump automatically turns off } \\
\text { ( } t_{j} \leq t_{\text {off }} \text { ), or when it is needed to meet the balance of the } \\
\text { building heating requirement, (W) }\end{array}$ \\
\hline RPM & $=$ & speed, (revolutions/min) \\
\hline SEER & $=$ & seasonal energy efficiency ratio, (Btu/(W॰h)) \\
\hline $\mathrm{T}_{\mathrm{D}}$ & $=$ & outdoor design temperature as specified in Table $4,\left({ }^{\circ} \mathrm{F}\right)$ \\
\hline$T_{\text {off }}$ & $=$ & compressor time-off, (h) \\
\hline Ton & $=$ & compressor time-on, (h) \\
\hline$t$ & $=$ & outdoor temperature, $\left({ }^{\circ} \mathrm{F}\right)$ \\
\hline$t_{j}$ & $=$ & representative outdoor temperature for temperature bin $\mathrm{j}\left({ }^{\circ} \mathrm{F}\right)$ \\
\hline$t_{1}$ & $=$ & $\begin{array}{l}\text { outdoor temperature in cooling at which the building load is } \\
\text { equal to capacity of the system operating at the minimum } \\
\left.\text { compressor speed, ( }{ }^{\circ} \mathrm{F}\right)\end{array}$ \\
\hline$\tau_{2}$ & $=$ & $\begin{array}{l}\text { outdoor temperature in cooling at which the building load is } \\
\text { equal to capacity of the system operating at the maximum } \\
\left.\text { compressor speed, ( }{ }^{\circ} \mathrm{F}\right)\end{array}$ \\
\hline$t_{3}$ & $=$ & $\begin{array}{l}\text { outdoor temperature in heating at which the building load is } \\
\text { equal to capacity of the system operating at the minimum } \\
\text { compressor speed, }\left({ }^{\circ} \mathrm{F}\right)\end{array}$ \\
\hline$t_{4}$ & $=$ & $\begin{array}{l}\text { outdoor temperature in heating at which the building load is } \\
\text { equal to capacity of the system operating at the maximum } \\
\text { compressor speed, }\left({ }^{\circ} \mathrm{F}\right)\end{array}$ \\
\hline$t_{\text {on }}$ & $=$ & $\begin{array}{l}\text { outdoor temperature at which the compressor is automatically } \\
\text { turned on after low-temperature shut-off, }\left({ }^{\circ} \mathrm{F}\right)\end{array}$ \\
\hline
\end{tabular}




$\begin{array}{ll}t_{\text {off }}= & \begin{array}{l}\text { outdoor temperature at which the compressor is automatically } \\ \text { turned off to avoid operation at low temperatures, }\left({ }^{\circ} \mathrm{F}\right)\end{array} \\ t_{\mathrm{vc}} & =\begin{array}{l}\text { outdoor temperature at which the building cooling load is } \\ \text { equal to system capacity while operating at the compressor } \\ \text { speed prescribed for the intermediate speed test, }\left({ }^{\circ} \mathrm{F}\right)\end{array} \\ t_{\mathrm{vh}} & \begin{array}{l}\text { outdoor temperature at which the building heating load is } \\ \text { equal to system capacity while operating at the compressor }\end{array} \\ \mathrm{x}\left(t_{\mathrm{j}}\right)= & \text { speed prescribed for the intermediate speed test, }\left({ }^{\circ} \mathrm{F}\right) \\ \delta\left(t_{j}\right)= & \text { cooling or heating load factor at a bin temperature } t_{j},(-)\end{array}$

Superscripts:
$\mathrm{k}=\mathrm{n} \quad=$ nominal compressor speed
$\mathrm{k}=1 \quad=$ the minimum compressor speed
$\mathrm{k}=2 \quad=\quad$ the maximum compressor speed
$\mathrm{k}=\mathrm{i}=$ the intermediate speed specified for the intermediate speed test
$\mathrm{k}=\mathrm{v} \quad=$ an intermediate speed at which the unit capacity matches the building load at specified outdoor temperature

Subscripts:

\begin{tabular}{|c|c|c|}
\hline $\operatorname{def}$ & $=$ & defrost \\
\hline f & $=$ & indoor fan \\
\hline i & $=$ & intermediate speed test \\
\hline $\max$ & $=$ & maximum \\
\hline $\min$ & $=$ & minimum \\
\hline $\mathbf{s}$ & $=$ & single speed \\
\hline ss & $=$ & steady state \\
\hline$y$ & $=$ & variable speed \\
\hline
\end{tabular}




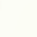




\section{INTRODUCTION}

Most residential air conditioners and heat pumps employ single speed compressors and single speed fans. Such systems can provide only one level of capacity at given operating conditions. More advanced systems employing two speed compressors can provide two levels of capacity at given operating conditions. The distinguishing feature of variable speed systems is that their compressors can operate at different speeds and allow capacity to modulate within a certain range.

The interrelation between the building load and capacity of a variable speed system in the cooling mode is shown graphically in Figure 1. The diagonal line originating at the intersection of the ordinate and abscissa is the building load line. The line defined by system capacities at the maximum compressor speed, $Q_{s s}^{k=2}(82)$ and $Q_{s s}^{k=2}(95)$, provides a simplified representation of system capacity at the maximum compressor speed at different outdoor temperatures. Similarly, capacities $Q_{s=1}^{k=1}(82)$ and $\mathrm{Q}_{\mathrm{s} s}^{\mathrm{k}=1}(67)$ prescribe the system capacity line at the minimum compressor speed.

Because of the capacity range a variable speed system can provide, it has two balance points in a given installation, and three modes of operation as shown for the cooling mode in Figure 1. The low speed balance point, depicted as $t_{1}$, is the outdoor temperature at which the capacity line at the minimum compressor speed intersects the building load line. The high speed balance point, depicted as $t_{2}$, is the outdoor temperature at which the capacity line at the maximum compressor speed intersects the building 


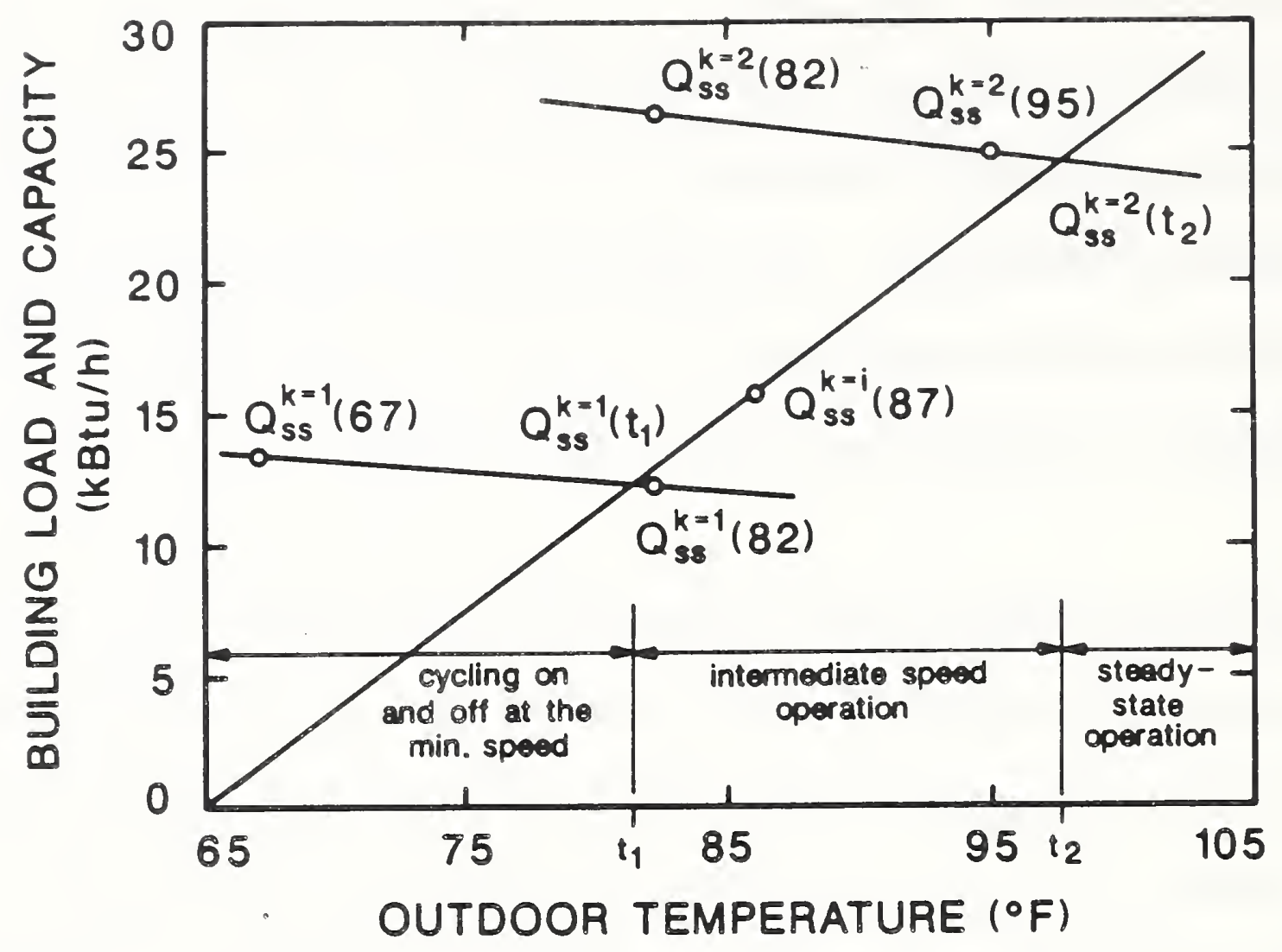

Figure 1. Building cooling load and capacity of a variable speed air conditioner.

load line. These two balance points separate three outdoor temperature ranges corresponding to three cases of operation of a variable speed unit:

$65^{\circ} \mathrm{F}$ to $t_{1}$ - system cycles on and off at the minimum compressor speed to match the building load, case I $t_{1}$ to $t_{2}$ - system operates continuously at an intermediate compressor speed to deliver the capacity that matches the building load, case II.

$t_{2}$ to $105^{\circ} \mathrm{F}$ - system operates continuously at the maximum compressor speed, case III. 
Operation of a variable speed system at the outdoor temperature ranges from $65^{\circ} \mathrm{F}$ to $t_{1}$ (case I) and from $t_{2}$ to $105^{\circ} \mathrm{F}$ (case III) is similar to the operation of a two speed unit. As a result, appropriate portions of a two speed unit rating procedure can be, with no or little modifications, applied to represent performance of variable speed equipment. However, for the outdoor temperature range between the two balance points (case II) the existing U.S. Department of Energy (DoE) procedures [1] can not represent adequately the performance of a variable speed system. Similarly, three cases of operation of variable speed equipment can be identified in the heating mode with no procedure available to account for performance in the intermediate speed region. Consequently, new procedures are developed in this report to allow rating of variable speed systems.

This report presents analysis and development of a rating procedure for a variable speed system. At the time the analysis was performed no variable speed system was available on the market, making it impossible to base the procedure on NBS tests of actual units. The rating procedure was prepared based on NBS experience with other residential heat pump products for which rating procedures exist, and also based on industry waiver petitions to DoE test procedures, and on comments on the DoE proposed procedure for variable speed systems [2].

This procedure evolved from the existing DoE procedures for single speed and two speed systems [1]. Section 2 of this document describes, as a background, only modifications and enhancements made to the existing procedures to rate variable speed equipment. Reader's familiarity with the 
existing procedures is assumed. This procedure has been prepared for DoE as a NBS recommendation in the rule making process.

\section{BACKGROUND OF THE PROCEDURE DEVELOPMENT}

\subsection{The Intermediate Speed Test}

The main shortcoming of the existing rating procedure [1] with respect to variable speed systems is that it cannot adequately represent performance of variable speed equipment in the intermediate speed range. Consequently, each manufacturer who planned to develop and market a variable speed system formulated his own rating procedure and petitioned DoE for approval as a waiver.

The first variable speed rating procedure was proposed by Borg-Wagner [3] and was basically adopted in ARI Standard 210/240 [4]. As the major concern was an accurate representation of a non-linear power input profile in the intermediate speed operation range, the procedure introduced an intermediate speed test in the cooling and heating mode at $87^{\circ} \mathrm{F}$ and $35^{\circ} \mathrm{F}$ outdoor temperature, respectively. Taking into account bin hour distributions and practical considerations, the selection of these outdoor temperatures as test conditions was appropriate and was followed by other manufactures in their waiver petitions.

The available points for power interpolation are shown for the cooling mode in Figure 2. The two points at the edges of the intermediate speed region, $E_{s s}^{k=1}\left(t_{1}\right)$ and $E_{s s}^{k=2}\left(t_{2}\right)$, can be calculated from the minimum and 
maximum speed capacity and power input equations, and the building load algorithm. The point, $E_{s=1}^{k=1}(87)$, is the additional datum obtained from the intermediate speed test. This third point allows for a better representation of the non-linear power input profile, which otherwise would have to be prescribed by a straight line connecting $E_{s s}^{k=1}\left(t_{1}\right)$ and $E_{s s}^{k=2}\left(t_{2}\right)$, as shown by the short dashed line in Figure 2, overestimating the power input.

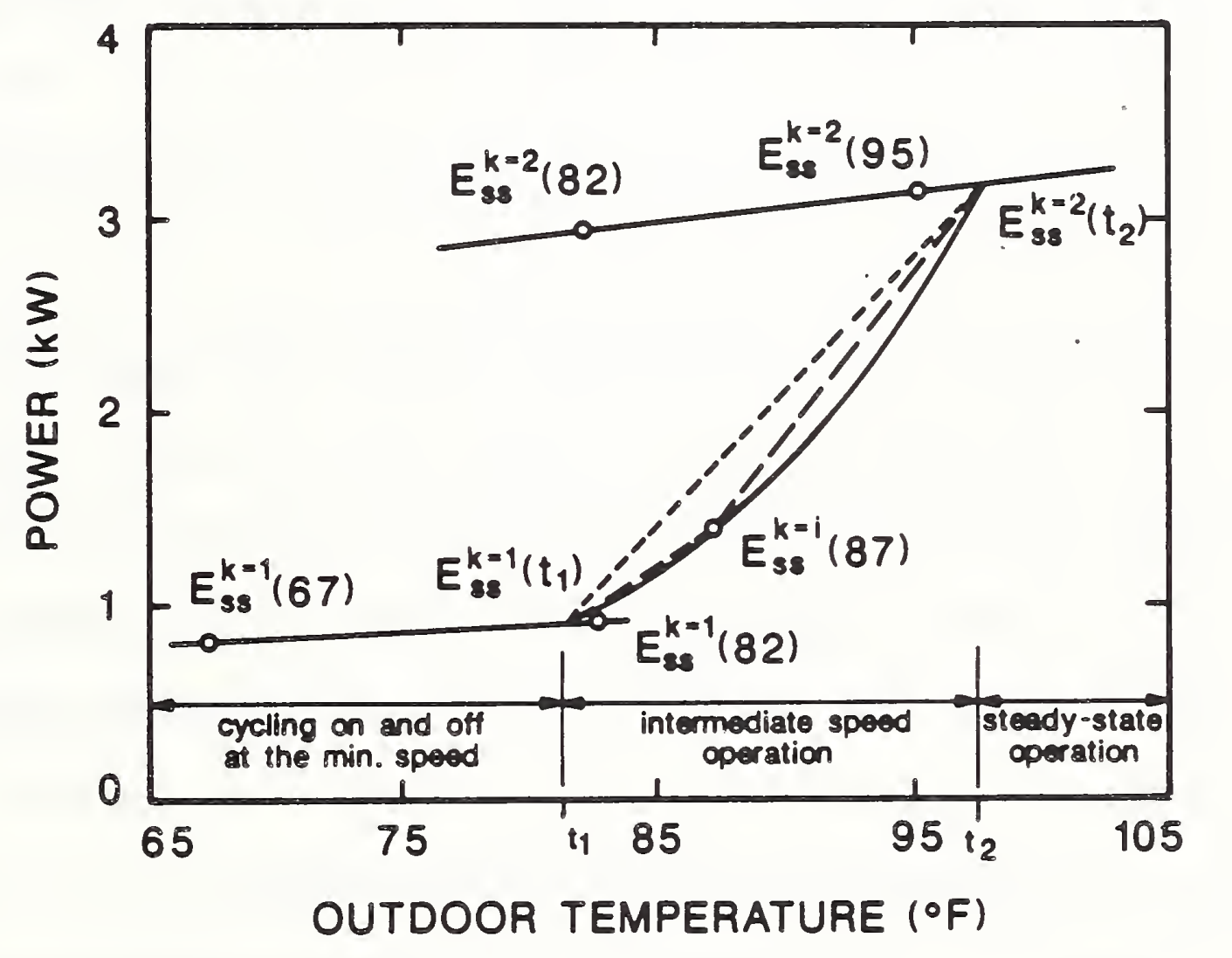

-.- linear interpolation of power using two points

- linear interpolation of power using three points

- transposed from linear interpolation of EER using three points; expected shape of typical characteristic curve

Figure 2. System power at intermediate speed operation using different interpolations. 
The ARI procedure [4] requires the system capacities during the intermediate speed tests to be equal to the respective building loads calculated for the outdoor temperatures at which the cooling and heating tests are performed. The matching of loads and capacities should be obtained by the proper selection of compressor speeds. The matching requirement is much easier to satisfy in cooling than in the heating mode. To avoid an iterative testing at different speeds while searching for the speed at which matching occurs, Urbs et al, [5], proposed an algorithm which allows use of test data obtained when the capacity does not match the load. The algorithm uses capacity slopes at the maximum and minimum compressor speeds. By weighing these slopes, the capacity line for the intermediate compressor speed at which the test was performed is determined. The power line at the intermediate speed is similarly obtained. Having prescribed capacity and the building load lines, the temperature can be found at which both lines intersect, i.e. in which the system operating at the tested intermediate speed matches the building load. The power input to the system is then evaluated at this temperature, and this value is used in interpolation of power for the intermediate speed operation range. For details on this algorithm the reader may refer to the original publication. NBS found this procedure adequate and highly practical, and adopted it in this proposed rating procedure for variable speed systems. Once it is accepted that a match between the building load and the system capacity is not necessarily needed, the selection of the compressor speed for the intermediate speed test had to be otherwise defined. A strict prescription of the speed is preferable for rating verification. 
Again, the objective of speed selection is to obtain capacity that would match or be close to the building load. The task of prescribing such speed for different systems in a standardized way appeared to be quite difficult because different systems possess different capacity VS RPM characteristics, dependent on electric drive and compressor characteristics, control strategy relating fan speeds to the compressor speed, expansion device characteristics, etc.

After a review of the waiver procedures for variable speed systems of two manufacturers $[6,7]$, the following equation is proposed for prescribing the speed for the intermediate speed test in the cooling mode:

intermediate speed $=$ minimum speed $+($ maximum speed - minimum $s p e e d) / 3$

For the heating mode, the same speed as for cooling is prescribed. If the unit controls allow frequency to be changed only in discrete steps such that the prescribed speed cannot be attained in the tested equipment, the test should be performed at the next higher input frequency level available in the system.

The above paragraphs identify the compressor speed at which the intermediate speed test should be attempted to run. However, constant compressor speed may be difficult to maintain and, therefore, the following variations from the prescribed speed should be allowed: 
those associated with variations of the input line frequency and instability of controls. These variations should not result in decrease of the compressor speed below the speed calculated by equation (2.1); if this happened to be the case, the test should be performed at the next higher available speed step.

those associated with control strategies which control speed in the field during frosting/defrosting operation: during the initial period after switching from defrosting into heating, in the final period of the heating portion of the frost accumulation cycle, and during defrosting. Variation of the compressor speed from the test value shall be allowed in these instances to the same extent and for the same period of time as such variations would occur in the field due to control strategy.

\subsection{Interpolation of the Intermediate Speed Power Input}

The ARI procedure for variable speed equipment [4] as well as waiver procedures of individual manufacturers $[3,6,7]$ evaluated the power input in the intermediate speed range by applying linear interpolation between the three known data points; the power at the minimum speed balance point, $E_{s s}^{k=1}\left(t_{1}\right)$, the power at the intermediate speed test, $E_{s s}^{k=i}(87)$, and the power at the maximum speed balance point, $E_{s s}^{k=2}\left(t_{2}\right)$. This method is shown for the cooling mode in Figure 2 by the long dashed line.

It was recognized from the beginning that additional intermediate speed tests at other than $87^{\circ} \mathrm{F}$ and $35^{\circ} \mathrm{F}$ temperatures would further improve the rating of a variable speed product. However, because of the increased testing 
burden, the manufacturers who submitted waver petitions for their variable speed products opted for one intermediate test point and a lower rating. An improved calculation procedure for seasonal performance of a variable speed system (that would provide a rating closer to real system performance) can be formulated by introducing two modifications to the existing methods:

1. instead of interpolating the power input, performing EER or COP interpolation and then calculating the power input values by dividing capacity by EER or COP, respectively, 2. using parabolic instead of a linear interpolation.

The advantage of interpolating EER rather than power can be deduced by examining Figure 2 and Figure 3. The figures show system power and efficiency lines in the intermediate speed operation range in the cooling mode. The shape of the lines depends on the interpolation method used. The short dashed Iine in Figure 2 connecting system power inputs, $E_{s s}^{k=1}\left(t_{1}\right)$ and $E_{s s}^{k=2}\left(t_{2}\right)$, at the minimum and maximum compressor speeds, respectively, represents most conservative power input assessment. The long dashed line connecting system powers at $t_{1}, 87^{\circ} \mathrm{F}$ and $t_{2}$ represents the interpolation method used in ARI Standard 210/240. Experimental evidence has shown that none of these lines prescribe adequately the system power but rather the solid line provide a realistic representation of the power input.

As system power and EER are related through system capacity, $(E E R=$ capacity/power $)$ it is of interest to examine the shape of EER Iines (Figure 3 ) in the intermediate speed range in relation to selected 


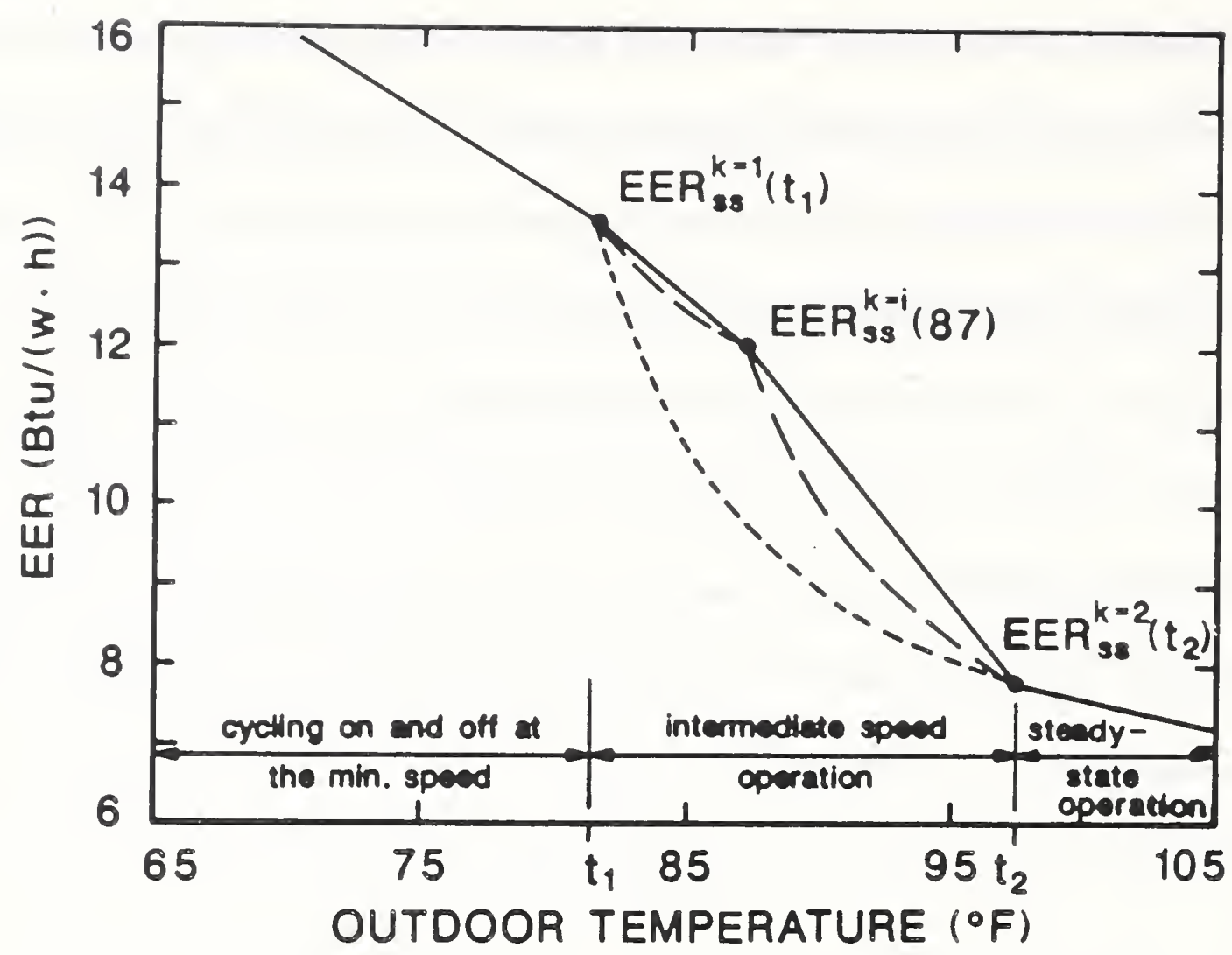

...- transposed from linear interpolation of power using two points

- transposed from linear interpolation of power using three points

- linear intexpolation of EER using three points

Figure 3. System EER at intermediate speed operation using different interpolations.

interpolating methods of the system power shown in Figure 2. There is a direct relationship between the line pattern shown in Figure 2 and Figure 3 ; i.e. the short dashed line representing EER in Figure 3 corresponds to the assumption that the system power changes linearly between $t_{1}$ and $t_{2}$ as shown by the short dashed line in Figure 2. Linear interpolation of power between the three points results in an unrealistic shape of the EER line in Figure 3. The continuous line in the intermediate region in Figure 3 represents a linear interpolation of EER between three points. This linear interpolation of EER results in a realistic representation of the system power as shown by the solid concave line in Figure 2 . 
In brief, the power input to a variable speed system in the intermediate speed operating range, can be estimated by interpolating either system power or system EER. The parameter selected for interpolation should be the one which is more linear in the interpolation region. The experimental evidence is that EER is a more linear parameter than power.

Having chosen EER for interpolation in the intermediate speed operation range, it is not inconsequential which interpolation method is applied. The parabolic interpolation method, as compared to the linear, has two important advantages:

- unlike the power line, the EER line in the intermediate speed range may be either convex or concave. The reason that this line may be concave or convex is that, since it is nearly linear, a small deviation in system characteristics in either direction will cause it to be either above (convex) or below (concave) linearity. A straight line interpolation of EER would unduly benefit systems with a concave EER line.

- from the comments received from the industry on the proposed procedure for variable speed systems it appears that the EER line is indeed of a second or higher order. Although different systems may have different characteristics, a parabolic fit should give the best estimate of the EER line with three performance points available.

Although the above analysis refers to the cooling mode, the same conclusions hold for the heating mode. Consequently, the recommended rating procedure uses parabolic interpolation of an efficiency descriptor (EER or COP) for representation of system performance over the intermediate speed range in 
both cooling and heating. The recommended form of the interpolation equation is $\mathrm{y}=\mathrm{a}+\mathrm{b} \cdot \mathrm{x}+\mathrm{b} \cdot \mathrm{x}^{2}$.

\subsection{Cyclic Test}

The cooling cyclic test for single speed systems and two speed systems is prescribed at an outdoor $82^{\circ} \mathrm{F}$ temperature [1]. The cyclic test for variable speed systems is specified in ARI Standard 210/240 [4] at an outdoor temperature of $67^{\circ} \mathrm{F}$. Although the $67^{\circ} \mathrm{F}$ temperature constitutes a departure from the standard cyclic test $82^{\circ} \mathrm{F}$ condition, it has been adopted in the procedure contained in this report. This selection is based on the practical consideration of assigning a cyclic test at the same outdoor temperature as one of the wet coil tests. Because variable speed systems are expected to operate at the minimum speed in the outdoor temperature range from $65^{\circ} \mathrm{F}$ to approximately $80^{\circ} \mathrm{F}$ (depending on the capacity modulation ratio), minimum speed wet coil test outdoor temperatures were selected to be $82^{\circ} \mathrm{F}$ and $67^{\circ} \mathrm{F}$. Since a variable speed system is not likely to cycle in the field at an outdoor temperature above $80^{\circ} \mathrm{F}$, the temperature of $67^{\circ} \mathrm{F}$ seems to be the better selection for the cyclic test. For similar reasons, the ARI Standard $210 / 24062^{\circ} \mathrm{F}$ outdoor temperature for heating cyclic test was also adopted.

It should be pointed out that NBS laboratory cyclic tests performed on a single speed system showed insignificant dependence of the $C_{D}$ value on the outdoor temperature as long as the compressor time-on and time-off are preserved. The $C_{D}$ values for tests at outdoor temperatures of $95^{\circ} \mathrm{F}, 82^{\circ} \mathrm{F}$, and $70^{\circ} \mathrm{F}$ were the same within the experimental error. 
Another departure from the single speed cyclic test is the length of the time-on and time-off. Since a variable speed system will start to cycle "on" and "off" at a much lower outdoor temperature than a single speed system, the variable speed unit should be allowed more than 6 minutes time-on during the cyclic test. An analysis using simple thermostat equations will allow derivation of appropriate time-on, time-off, and cycling rate values for variable speed equipment.

Figure 4 presents a typical parabolic curve representing the compressor cycling rate as a function of the cooling load. The upper graph describes the compressor cycling rate for a single speed system whose capacity line coincides with the capacity of a variable speed system operating at the maximum speed. The lower graph describes the cycling rate of the variable speed system. Cycling starts at the building load equal to $Q_{s}\left(t_{2}\right)$ for the single speed system (which is equal to $Q_{s s}^{k=2}\left(t_{2}\right)$ of the equivalent variable speed system), and at the building load equal to $Q_{s}^{k=1}\left(t_{1}\right)$ for the variable speed system.

In order to find the cycling rate of the variable speed system, the relationship between the time-on and time-off periods for the variable and single speed systems must be first determined. Since both units would be installed in the same structure, the same building load would have to be satisfied. Also, assuming that the thermostat band is the same for both systems, the same amount of heat would have to be transferred to the house (independently of the outdoor temperature) to trigger a compressor in each system, i.e. $B L\left(t_{j}\right) \cdot T_{o f f}\left(t_{j}\right)=$ const. 

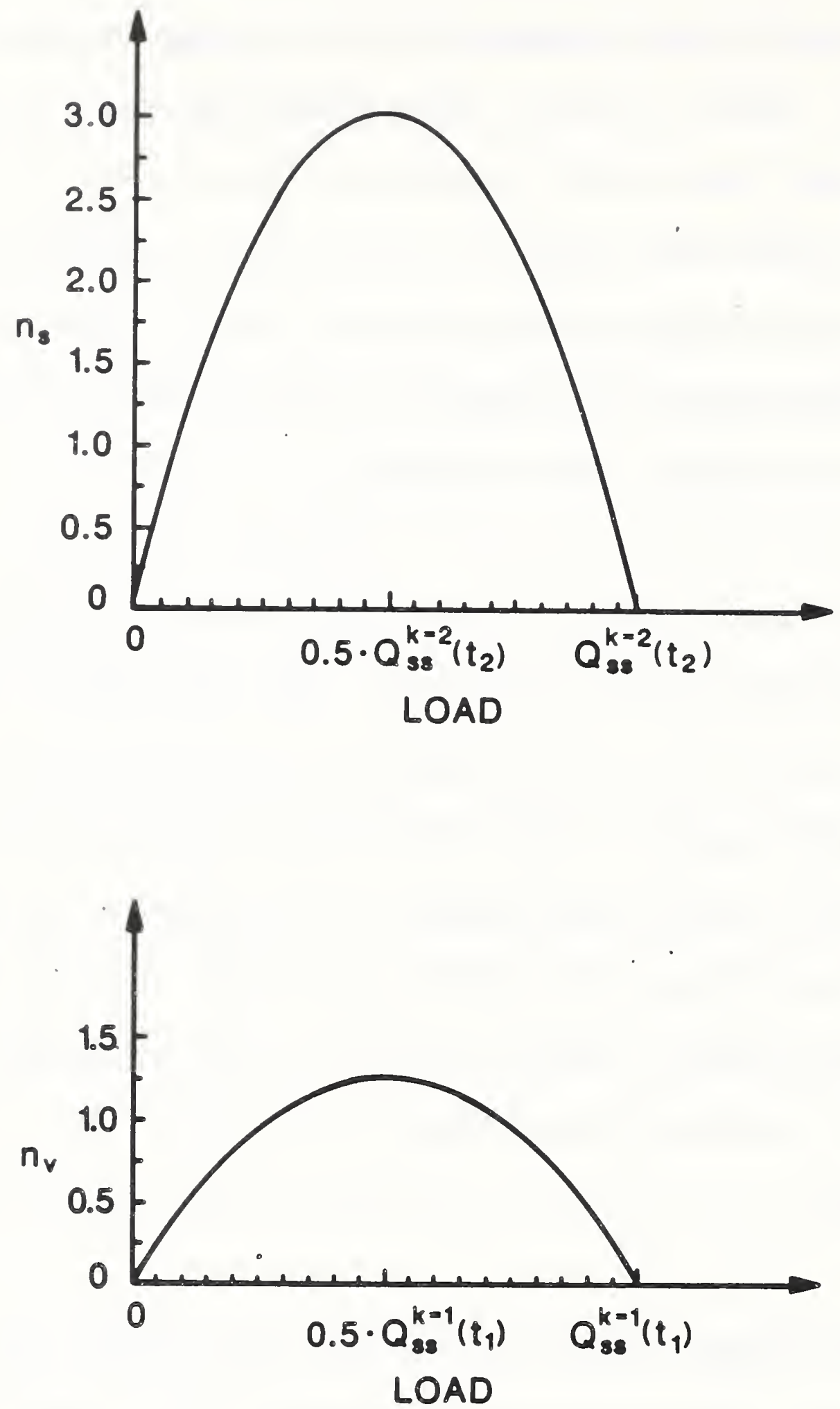

Figure 4. Cycling rate for a single speed system, $n_{s}$, and a variable speed system, $n_{v}$.

In order to find time-off for the variable speed system, we may write this equation for both systems for the same load fraction and equate both sides; for example, for a 20 fraction, 
$T_{\text {off, s }} \cdot 0.2 \cdot Q_{s s}^{k=2}\left(t_{2}\right)=T_{\text {off, }} \cdot 0.2 \cdot Q_{s s}^{k=1}\left(t_{1}\right)$

where: $T_{o f f, s}$ and $T_{\circ f f, v}$ are time-off of single speed and variable speed systems, respectively.

Consequently,

$T_{\text {off, } f}=T_{\text {off,s }} \cdot Q_{s s}^{k=2}\left(t_{2}\right) / Q_{s s}^{k=1}\left(t_{1}\right)$

Assuming the start-up characteristics of both systems are similar and the percentages of time-on and time-off are preserved, time-on for the variable speed system, $T_{o n, v}$, may be expressed as a function of the time-on of the equivalent single speed system, $T_{o n}, s$.

$T_{o n, v}=T_{o n, s} \cdot Q_{s s}^{k=2}\left(t_{2}\right) / Q_{s s}^{k=1}\left(t_{1}\right)$

Employing equations (2.3) and (2.4), the cycling rate of the variable speed system, $n_{v}$, in relation to the cycling rate of the single speed system, $n_{s}$ is determined.

$n_{v}=n_{s} \cdot Q_{s s}^{k=1}\left(t_{1}\right) / Q_{s}^{k=2}\left(t_{2}\right)$

The above equations, although derived with some simplifications, could serve as an algorithm for determining time-on and time-off during the cycling test of a variable speed system. The equations would allow a variable speed system with a greater capacity modulation ratio, $\mathrm{Q}_{\mathrm{ss}}^{\mathrm{k}=2}\left(t_{2}\right) / \mathrm{Q}_{\mathrm{ss}}^{\mathrm{k}=1}\left(t_{1}\right)$, to have longer compressor time-on during the test which would result in a lower value of the cyclic degradation coefficient, $C_{D}$. However, applying these equations could result in a long and costly 
cyclic test. For a capacity modulation ratio of 2 , the cyclic test would last one hour, but two hours would be required for a system having a capacity modulation ratio of 3 . Conversely, the benefit of a lower $C_{D}$ value is smaller for systems with a higher capacity modulation ratio since the systems cycles less often. The decreasing effect of $C_{D}$ on the Seasonal Energy Efficiency Ratio, SEER, is shown in Figure 5. The figure shows the maximum theoretical penalty in SEER which we define as a difference in the SEER value calculated with $C_{D}=0.25$ and $C_{D}=0$. The figure shows that, from a practical standpoint, there is no reason to run long cyclic tests for high capacity modulation systems since the $C_{D}$ improvement will not justify the increased burden of a prolonged test. As a result, a fixed time-on equal to 12 minutes is prescribed in the proposed procedure for systems having a capacity modulation ratio of 2 or

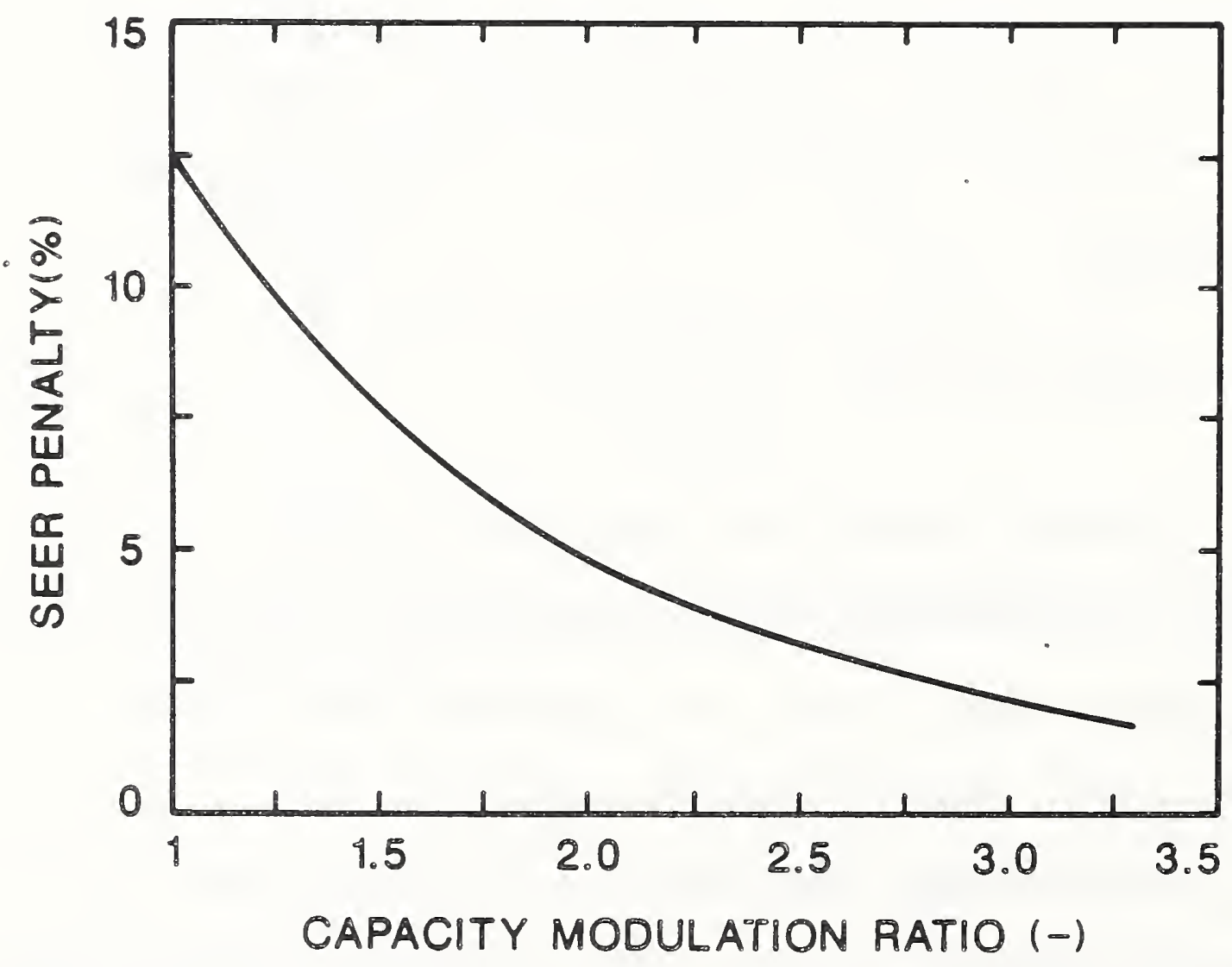

Figure 5. Maximum theoretical SEER penalty at default $C_{D}$. 
more. The equations presented above are recommended for systems having capacity modulation ratio smaller than 2 .

As was done for the cooling mode, a similar analysis can be repeated for the heating mode. The situation in the heating mode is more complicated because of a range of building loads (between the maximum and minimum) prescribed by the DoE rating procedure [1]. If the steps of the cooling mode analysis are followed rigorously, different values for time-on and time off could be prescribed for different building heating loads. A heat pump with a capacity modulation ratio of 2 in the cooling mode could have a compressor time-on between 9 minutes and 12 minutes in the heating mode, depending on the design heating requirement. For simplicity, the proposed procedure prescribes the heating mode time-on and time-off to be the same as for cooling cycling test.

2.4 Capacity and Power Input Lines at the Maximum Compressor Speed in the Heating Mode

The rating procedure for variable speed equipment contained in ARI Standard 210/240 [4] prescribes the capacity and power lines based on results of two tests at temperatures of $17^{\circ} \mathrm{F}$ and $47^{\circ} \mathrm{F}$. The same method was proposed in two waiver procedures $[6,7]$ submitted to DoE. This prescription of the capacity and power lines does not include degradation due to frost accumulation and, therefore, is inconsistent with reality and the rating procedures already in place for other equipment. The simplification of the linear representation of capacity and power characteristics based on $17^{\circ} \mathrm{F}$ and $47^{\circ} \mathrm{F}$ points, however, does not affect the Heating Seasonal 
Performance Factor (HSPF) value calculated for the minimum heating design requirement. This is due to the intersection between the minimum building load line and the maximum speed capacity line occurring in the neighborhood of $14^{\circ} \mathrm{F}$ for region $\mathrm{V}$, and in the neighborhood of $19^{\circ} \mathrm{F}$ for the other regions. Thus, the method of representation of capacity and power used in previous procedures $[4,6,7]$ does not affect the HSPF value for the minimum design heating requirement in region IV which is prominently used for marketing purposes. For higher design heating requirements, the linear representation underestimates the power input required to the electric heater and, as a result, overestimates the efficiency descriptor.

NBS believes that comparability of variable speed equipment and single speed equipment ratings should be maintained by including the frost accumulation test results at the maximum speed, $Q_{d e f}^{k=2}(35)$ and $E_{d e f}^{k=2}(35)$, in prescription of the capacity and power input lines. Since results of this test affect HSPF values derived for lesser used design requirements, NBS recommends that, as an alternative to test, the use of equations (2.6) and

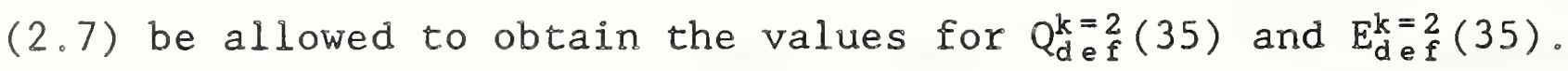

$\mathrm{Q}_{\mathrm{d} \text { ef }}^{\mathrm{k}=2}(35)=0.90 \cdot\left[\mathrm{Q}_{\mathrm{def}}^{\mathrm{k}=2}(17)+\left[\mathrm{Q}_{\mathrm{def}}^{\mathrm{k}=2}(47)-\mathrm{Q}_{\mathrm{def}}^{\mathrm{k}=2}(17)\right][35-17] /[47-17]\right]$

$E_{d e f}^{k=2}(35)=0.985 \cdot\left[E_{d e f}^{k=2}(17)+\left[E_{d e f}^{k=2}(47)-E_{d e f}^{k=2}(17)\right][35-17] /[47-17]\right]$ (2.7)

Correction factors of 10 percent for capacity and 1.5 percent for power in these equations were selected based on review of test data of ten single speed heat pumps [8] equipped with demand defrost (Figure 6 and 7). These 
correction factors result in COP degradation of $8.6 \%$ which is in line with COP degradation observed in the tested systems, as is shown in Figure 8.

2.5 Building Load in the Heating Mode.

It is likely that some variable speed systems which will be available commercially will be able to run at a higher compressor speed in the heating mode than in the cooling mode. As sizing of heat pumps is usually performed based on the cooling load, the ability to run at a higher maximum speed in the heating mode lowers the balance point - the temperature at which the electric heater is turned on by system controls. The efficiency benefit associated with the higher compressor speed in the heating mode depends on the relative position of the building load line

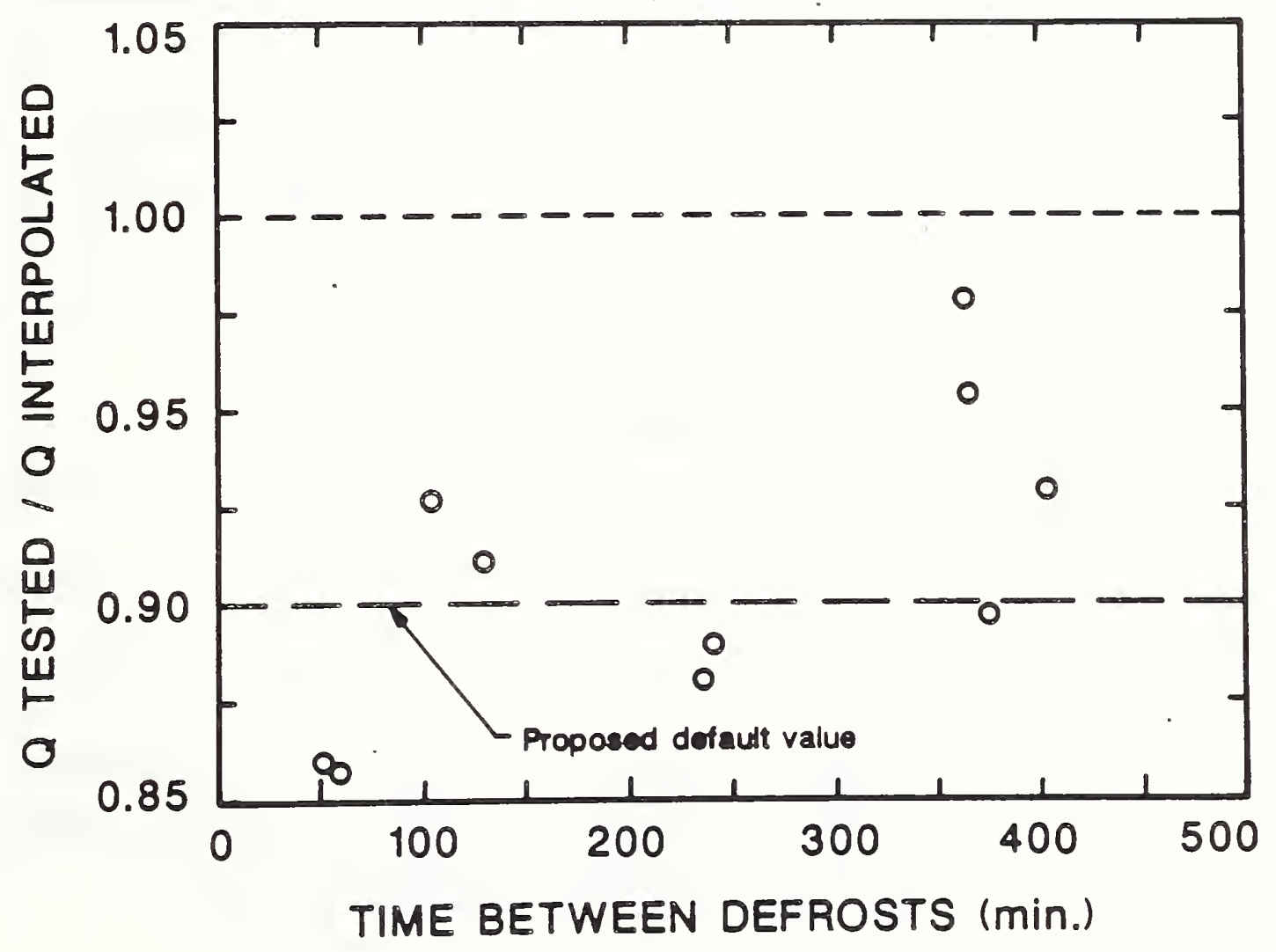

Figure 6. Ratio of measured capacity to linearly interpolated capacity (using $17^{\circ} \mathrm{F}$ and $47^{\circ} \mathrm{F}$ data) for the frost accumulation test. 
and the capacity line. The building load line, as prescribed in the existing procedures [1], is a function of capacity at $47^{\circ} \mathrm{F}$ outdoor temperature. If the system capacity at the maximum compressor speed, $\mathrm{Q}_{\mathrm{s} s}^{\mathrm{k}=2}(47)$, were used for the building load calculations, the calculated HSPF value would not be much different from the HSPF value calculated for a system operating at the same maximum speed in both heating and cooling.

In order to allow for an appropriate credit, the proposed procedure prescribes an optional, nominal capacity test at $47^{\circ} \mathrm{F}$ outdoor temperature. This test is applicable only if controls of the unit allow the compressor to run in the heating mode at a higher speed than in the cooling mode. The nominal capacity test should be performed at the compressor speed

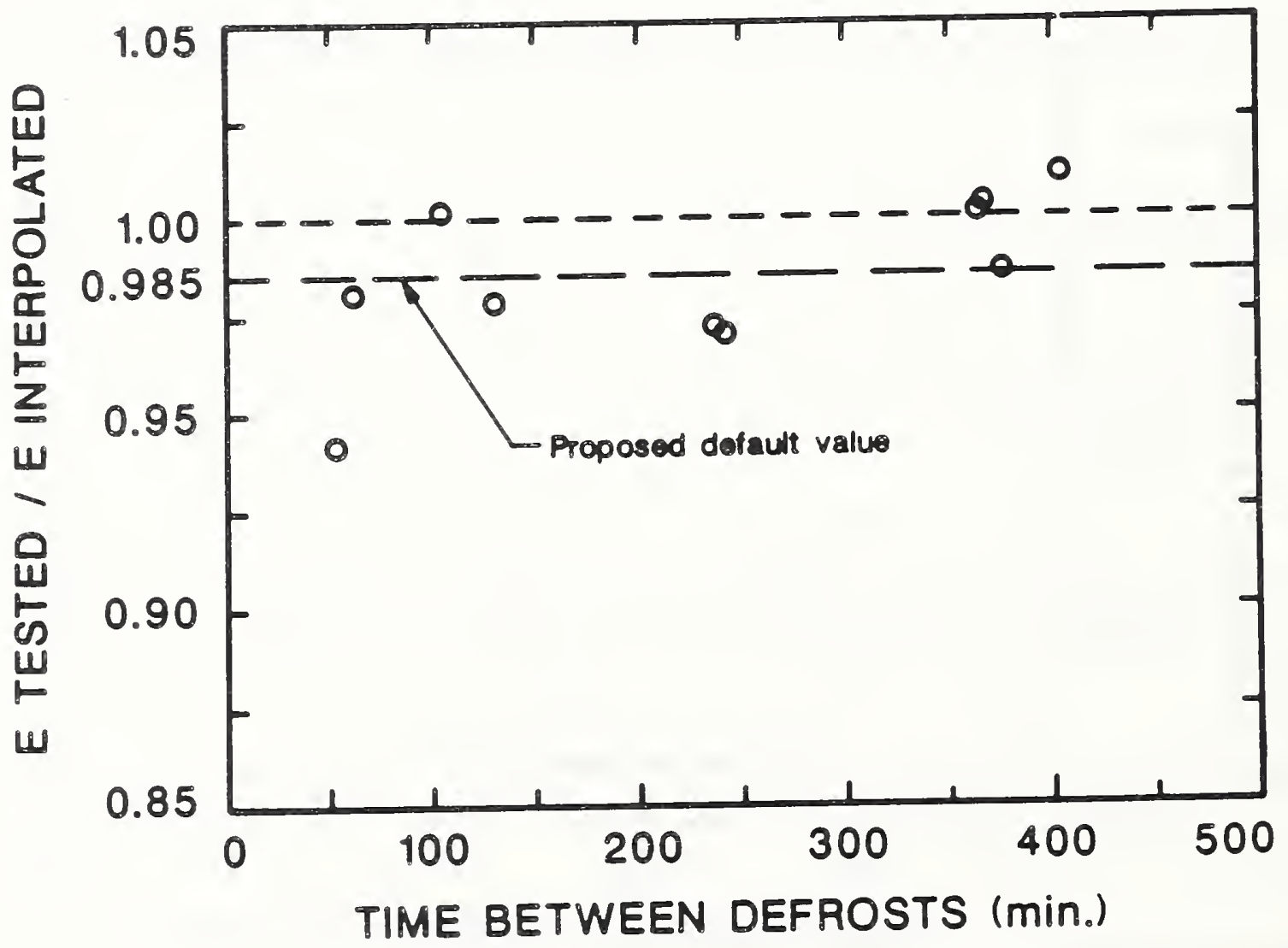

Figure 7. Ratio of measured power to linearly interpolated power (using $17^{\circ} \mathrm{F}$ and $47^{\circ} \mathrm{F}$ data) For the frost accumulation test. 


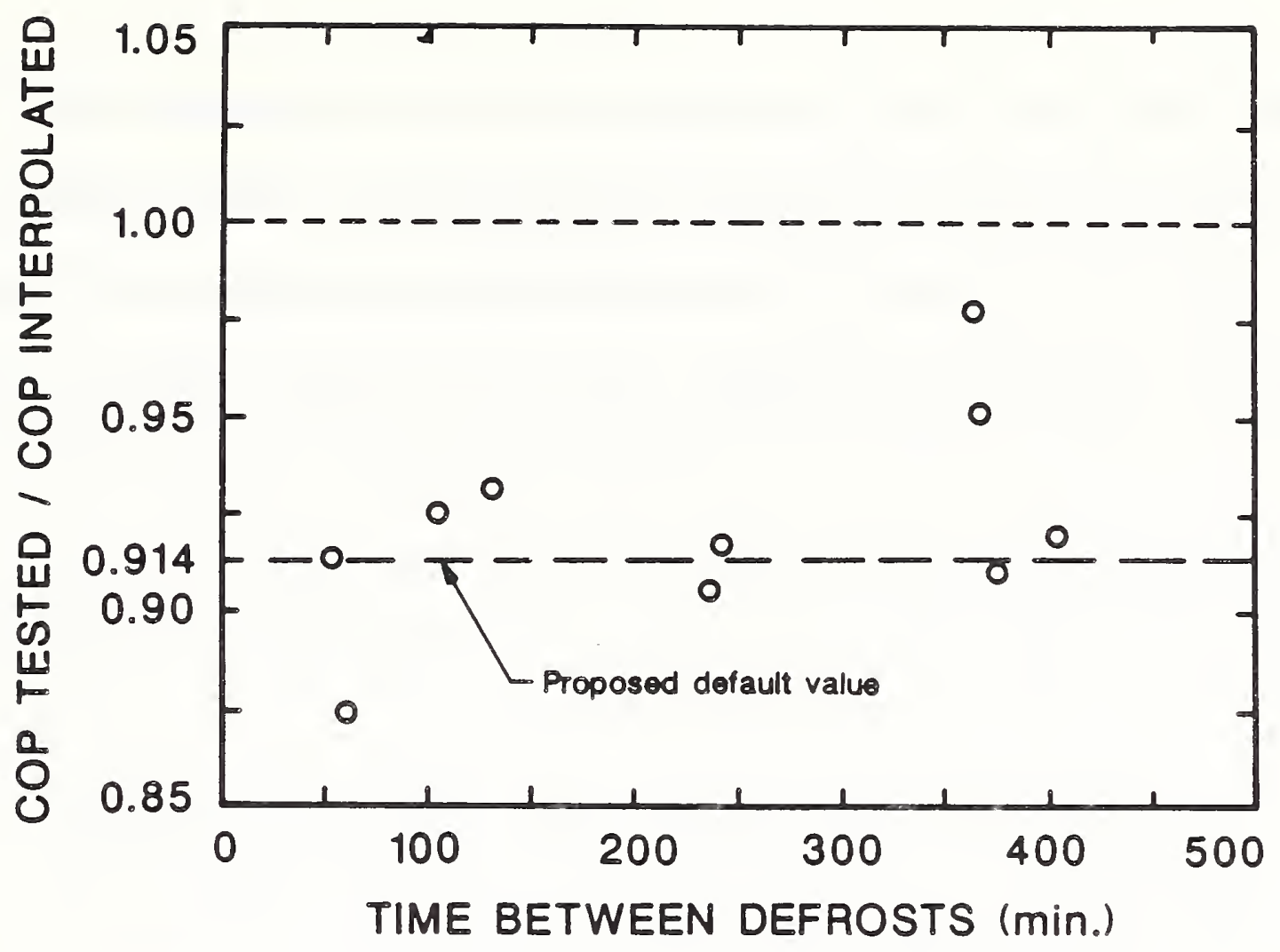

Figure 8. Ratio of measured $C O P$ to linearly interpolated COP (using $17^{\circ} \mathrm{F}$ and $47^{\circ} \mathrm{F}$ data) for the frost accumulation test.

equal to the compressor speed during the cooling test at $95^{\circ} \mathrm{F}$ temperature. The system capacity obtained in the nominal capacity test is to be used exclusively for evaluation of the design heating requirement.

\subsection{Measurement of the Electrical Energy Input}

The existing DoE rating procedure [1] requires measurement of the energy input to a system within 0.5 percent uncertainty. This requirement is not difficult to meet for single and two speed systems and, most likely, can be satisfied with an induction (rotating disc) type watthour meter.

Among the various types of variable speed drives possible, drives employing some kind of a solid state inverter are expected to be used in heat pumps. 
An undesirable feature of electric inverters is that they may inject large amounts of harmonic currents into the utility system. The amount of current wave distortion from its sinusoidal shape depends on the type of the inverter and its detailed design. For illustration, Figure 9 presents deformations of a current waveform recorded at the input to a three phase inverter. An informative presentation of different types of solid state inverters and their input and output current waveforms may be found in [9].

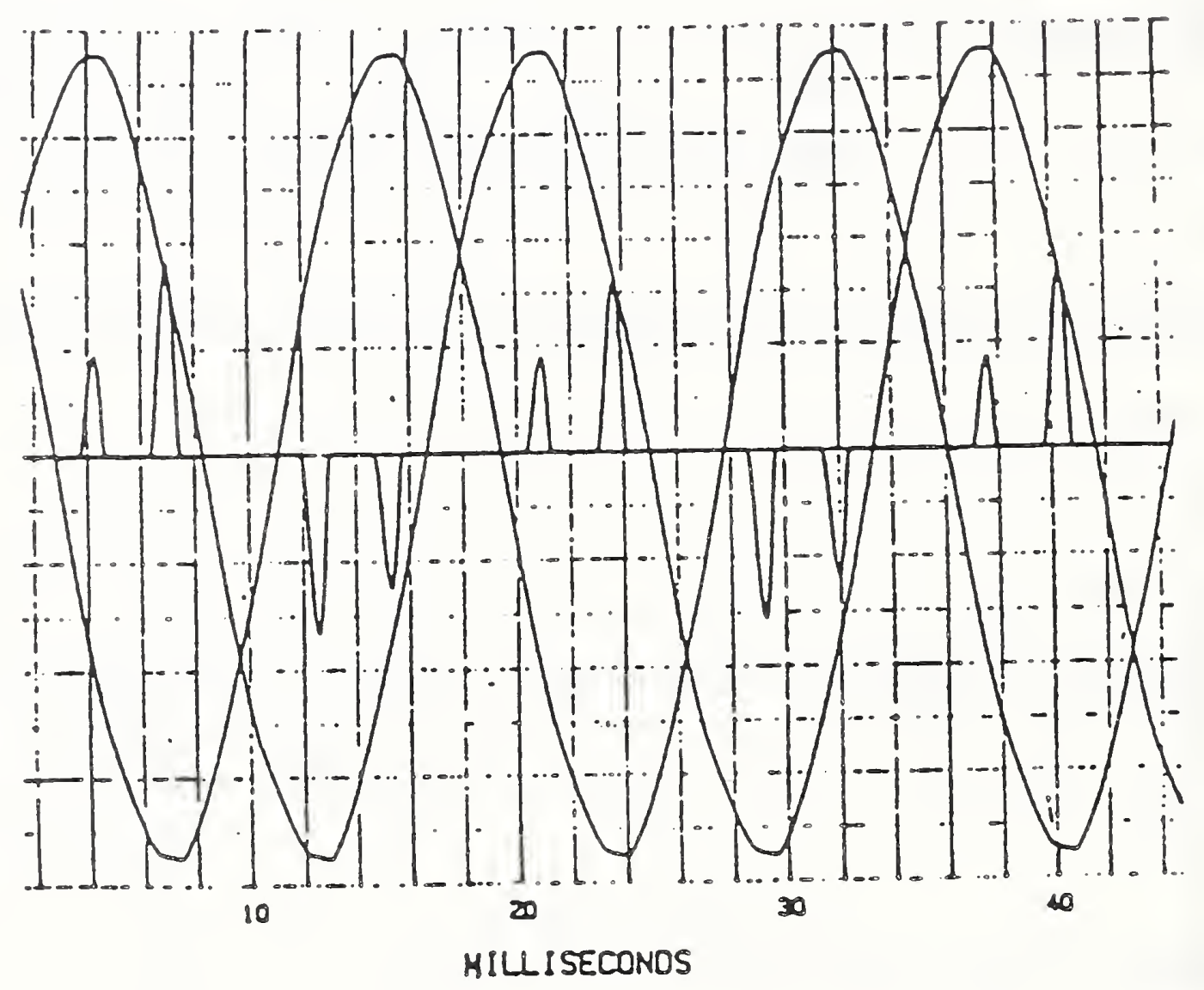

Figure 9. Deformation of the current waveform at input to a three phase inverter at $30 \mathrm{~Hz}$ output frequency (two voltage and one current waveforms are recorded).

Distortion of the current waveform on the line side makes the measurement of the energy input more difficult. Significant errors may occur if an inductive wathour meter if used. Baldwin et al. [10] conducted a series 
of tests on commercially available, self-contained, induction watthour meters. When exposed to current waveform distortion due to a variable-speed controller (three-phase), the meters over registered even if the voltage was undistorted at $60 \mathrm{~Hz}$. The average error was 2 percent with an individual meter over registering by as much as 6.7 percent.

Better accuracy of energy input measurement for distorted wave forms can be obtained with an electronic-type watthour metering device. However, our review of specifications of a number of electronic meters of different manufacturers showed that the measurement uncertainty of 0.5 percent cannot be obtained even with an electronic meter unless an excessively priced meter is used. Therefore, the proposed rating procedure specifies a relaxed uncertainty of 1 percent of the energy input measurement of systems employing a solid state inverter.

\subsection{Needed Research}

Numerous assumptions were made in the development of the proposed testing and rating procedure described in this report. Some assumption were related to performance characteristics in the intermediate speed region. One of the unknown aspects of system operation is its ability to closely follow the building load in the intermediate speed range. The proposed procedure assumes that the heat pump capacity exactly matches the building load at all times in the intermediate speed operation range. The penalty due to the compressor speed hunting in search of the matching capacity has not been evaluated. 
The frost accumulation test at the intermediate speed, as prescribed by the procedure, represents a significant departure from the intermediate speed operation in the field. To simplify the procedure, a constant compressor speed during the test is prescribed, while in field operation the compressor speed would increase with accumulation of frost to provide capacity matching the building load. Accumulation of frost provided significant complexity to the rating procedure for single speed systems; accurate representation of variable speed system performance when frosting of the outdoor coil occurs is even more difficult.

Since there was no variable speed equipment available on the market at the time of formulation of this rating procedure, NBS did not have its own laboratory data for support of the procedure development and relied on data and information made available by others $[11,12,13,14]$. It is believed that the proposed procedure captures the major performance characteristics common to most of the forthcoming variable speed products. It has to be realized, however, that continuous developments in electronics, sensors and control strategies will provide future systems with performance advantages that might not be accounted for within the presently proposed rating methodology. Thus the impact of system controls, frosting and load matching capability are all issues for further investigations. 
3. RATING PROCEDURE FOR VARIABLE SPEED SYSTEMS IN THE COOLING MODE

\subsection{Requirements for Testing Conditions and Testing Procedures}

Requirements regarding instruments and data acquisition systems, test apparatus, methods of test, test procedures, and data analysis are as prescribed in ASHRAE Standard 116-1983 [15] with the exception to the provisions specified in the following sections.

\subsubsection{Tests and Testing Conditions}

The tests and test conditions are presented in Table 1. The required tests include five wet coil tests $\left(A_{95}^{k=2}, B_{82}^{k=2}, B_{82}^{k=1}, B_{67}^{k=1}, I_{87}^{k=1}\right)$ and two dry coil tests $\left(C_{6}^{k=1}, D_{6}^{k=1}\right)$.

\subsubsection{Cyclic Test}

The cyclic test, $\mathrm{D}_{6}^{\mathrm{k}} 7^{1}$ (see Table 1 ), shall be conducted by cycling the unit "on" and "off" by manual or automatic operation of the normal control circuit of the unit. The unit shall cycle "on" and "off" with the compressor time-on, $\mathrm{T}_{\mathrm{on}}$, and time-off, $\mathrm{T}_{\mathrm{off}}$, determined as follows:

$\mathrm{T}_{\mathrm{on}}=\left\{\begin{array}{c}6 \cdot \frac{\mathrm{Q}_{\mathrm{ss}}^{\mathrm{k}=2}(95)}{\mathrm{Q}_{\mathrm{ss}}^{\mathrm{k}=1}(82)} \\ \text { 12, } \text { whichever is smaller }\end{array}\right.$

$\mathrm{T}_{\text {off }}=4 \cdot \mathrm{T}_{\mathrm{On}}$ 
The indoor fan and outdoor fan shall also cycle "on" and "off"; the duration of the fans "on" and "off" periods shall be governed by the automatic controls which the manufacturer normally supplies with the unit. The installation shall be designed to prevent air flow through the indoor unit due to natural or forced convection while the indoor fan is "off". This may be accomplished by installing dampers upstream and downstream of the test unit to block the "off" period air flow. Capacity integration shall be performed during the indoor fan "on" period. Power integration shall be performed over the total period of the cycle (time-on and timeoff).

During "on" time the compressor shall operate at the minimum speed unless the system controls have a preprogrammed start-up routine which causes the compressor to run at other than the minimum speed during the initial portion of the start-up period. In such a case, the compressor may follow the start-up routine during the test for the time and to the degree this would happen in the field.

The results of the cyclic test, $D_{67}^{k=1}$, shall be used in conjunction with the results of test $C_{67}^{k=1}$ to evaluate the cyclic degradation coefficient, $C_{D}$. Evaluation of $C_{D}$ shall be performed by using the algorithms prescribed in section 9.2.2 of ASHRAE Standard 116-1983 [15]. An assigned value of 0.25 may be used for the degradation coefficient, $C_{D}$, in lieu of conducting tests $C_{67}^{\mathrm{k}=1}$ and $D_{67}^{\mathrm{k}=1}$ 


\subsubsection{Intermediate Speed Test}

The intermediate speed test, $I_{8}^{k} 7^{i}$ (see Table 1), shall be conducted at the compressor speed evaluated by the equation:

$\mathrm{RPM}_{\mathrm{i}}=\mathrm{RPM}_{\mathrm{min}}+\left[\mathrm{RPM}_{\mathrm{max}}-\mathrm{RPM}_{\mathrm{min}}\right] / 3$

where: $\mathrm{RPM}_{i}=$ compressor speed during the intermediate speed test, (revolutions/min)

$$
\begin{aligned}
\mathrm{RPM}_{\text {min }}= & \begin{array}{l}
\text { minimum compressor speed in the cooling mode, } \\
(\text { revolutions } / \text { min) }
\end{array} \\
\mathrm{RPM}_{\text {max }}= & \begin{array}{l}
\text { maximum compressor speed in the cooling mode, } \\
(\text { revolutions } / \text { min) }
\end{array}
\end{aligned}
$$

The compressor input frequency may be used in lieu of the compressor speed to evaluate the compressor speed for the intermediate speed test. If the system controls allow varying the compressor speed only in discrete steps such that the calculated $\mathrm{RPM}_{i}$ cannot be attained by the system, the intermediate speed test shall be performed at the next higher compressor speed available. Variations from this speed are not allowed with the exception of those associated with line frequency variations and instability of the system controls. If these variations result in a decrease in the speed below the calculated $R P M_{i}$ value, the compressor speed selected for the test shall be increased.

\subsubsection{Air Quantity Measurement}

The air flow through the indoor and outdoor sections at any test shall be governed by system controls. The air flow shall meet the requirements of sections 5.1.3.3, 5.1.3.4, and 5.1.3.6 of ARI Standard 210/240-84 [4]. The minimum external pressure requirement (section 5.1.3.6 of [4]) applies 
only to tests with the maximum indoor air flow. The indoor air flow at lower than the maximum fan speed shall be determined by the equation:

$C F M=C F M_{\text {max }} \cdot \mathrm{RPM}_{\mathrm{f}} / \mathrm{RPM}_{\mathrm{f}, \mathrm{max}}$

where: $\mathrm{CFM}=$ volumetric flow rate at a lower than the maximum fan speed, $\left(\mathrm{ft}^{3} / \mathrm{min}\right)$

$\begin{aligned} & \mathrm{CFM}_{\mathrm{max}}= \begin{array}{l}\text { volumetric flow rate at the maximum fan speed, } \mathrm{RPM}_{\mathrm{f}, \mathrm{max}}, \\ \left(\mathrm{ft}^{3} / \mathrm{min}\right)\end{array} \\ & \mathrm{RPM}_{\mathrm{f}}= \text { indoor fan speed during a test, (revolutions/min) } \\ & \mathrm{RPM}_{\mathrm{f}, \max }=\text { maximum fan speed, (revolutions/min) }\end{aligned}$

\subsubsection{Power Measurement}

The power input to a system which employs an electrical inverter shall be measured with the aid of an instrument which is accurate to within \pm 1.0 percent of the quantity measured.

Due to the possibility of distorted voltage and current waveforms when an inverter is employed, an induction (rotating disc) type watthour meter may not provide the required accuracy for energy measurement for a variable speed system. The instrument which most likely can satisfy this accuracy requirement would cover a bandwidth of at least to $1 \mathrm{kHz}$. Because of the possibility of small dc-currents resulting from nonsymetrical switching, the use of current transformers may contribute additional errors.

\subsection{Calculation of Seasonal Energy Efficiency Ratio, SEER}

The building cooling load in bin temperature $t_{j}, B L\left(t_{j}\right)$, shall be calculated by the following equation: 
$\operatorname{BL}\left(t_{j}\right)=Q_{s s}^{k=2}(95) \frac{t_{j}-65}{1.1[95-65]} \quad(B t u / h)$

where: 1.1 = size factor for $10 z$ oversizing

The seasonal Energy Efficiency Ratio, SEER, shall be found by the following equation:

$\operatorname{SEER}=\frac{\sum_{j=1}^{8} n_{j} \cdot q\left(t_{j}\right)}{\sum_{j=1}^{8} n_{j} \cdot e\left(t_{j}\right)}$

where: $t_{j}=$ representative outdoor dry-bulb temperature for temperature bin $\mathrm{j},\left({ }^{\circ} \mathrm{F}\right)$

$n_{j}=$ fractional cooling bin hours in bin $j$, per Table 2.

$q\left(t_{j}\right)=$ cooling done in bin temperature $t_{j},(B t u / h)$

$e\left(t_{j}\right)=$ power input in bin temperature $t_{j}$, (W)

The terms $q\left(t_{j}\right)$ and $e\left(t_{j}\right)$ are evaluated at each bin temperature, shown in Table 2, by the following equations:

$q\left(t_{j}\right)=X\left(t_{j}\right) \cdot Q\left(t_{j}\right)$
$e\left(t_{j}\right)=X\left(t_{j}\right) \cdot E\left(t_{j}\right) / \operatorname{PLF}(X)$ 
where: $Q\left(t_{j}\right)=$ system cooling capacity at bin temperature $t_{j}$ at the speed at which capacity matches the building load, (Btu/h)

$$
\begin{aligned}
E\left(t_{j}\right)= & \text { system power input at bin temperature } t_{j} \text { during steady } \\
& \text { state operation, (W) } \\
X\left(t_{j}\right)= & \text { cooling load factor, (-) } \\
X\left(t_{j}\right)= & \left\{\begin{aligned}
B L\left(t_{j}\right) / Q\left(t_{j}\right) \text { if } B L\left(t_{j}\right) / Q\left(t_{j}\right)<1 \\
1 \text { otherwise }
\end{aligned}\right.
\end{aligned}
$$

$$
\operatorname{PLF}(\mathrm{X})=\text { part load factor, }(-)
$$

$$
\operatorname{PLF}(X)=1-C_{D}\left[1-X\left(t_{j}\right)\right]
$$

$$
C_{D}=\text { cyclic degradation coefficient, (-) }
$$

Quantities $Q\left(t_{j}\right)$ and $E\left(t_{j}\right)$ shall be evaluated according to three possible cases depending on compressor operation, as shown in Figure 1. These three cases can be identified in terms of the three outdoor temperature ranges or the two temperatures, $t_{1}$ and $t_{2}$, which separate them.

The outdoor temperature, $t_{1}$, at which the building load equals system capacity with the compressor operating at the minimum $(k=1)$ speed shall be calculated by the equation:

$\tau_{1}=\frac{975 \cdot Q_{s s}^{k=2}(95)+495 \cdot Q_{s s}^{k=1}(67)+2211 \cdot\left[Q_{s s}^{k=1}(67)-Q_{s s}^{k=1}(82)\right]}{15 \cdot Q_{s s}^{k=2}(95)+33 \cdot\left[Q_{s s}^{k=1}(67)-Q_{s s}^{k=1}(82)\right]}$ 
The outdoor temperature, $t_{2}$, at which the building load equals system capacity with the compressor operating at the maximum speed $(k=2)$ shall be calculated by the equation:

$t_{2}=\frac{845 \cdot Q_{s ~ s}^{k=2}(95)+429 \cdot Q_{s ~ s}^{k=2}(82)+2706 \cdot\left[Q_{s ~ s}^{k=2}(82)-Q_{s ~ s}^{k=2}(95)\right]}{33 \cdot Q_{s s}^{k=2}(82)-20 \cdot Q_{s ~}^{k=2}(95)}$

The equations for $\tau_{1}$, and $\tau_{2}$ were derived by equating the building load (eq. (3.5)) with system capacities at the minimum and maximum speeds, respectively (eqs. $(3.13)$ and $(3.32)$ ).

Case I, $\quad B L\left(t_{j}\right) \leq Q_{s s}^{k=1}\left(t_{j}\right), \quad\left(t_{j} \leq t_{1}\right)$

Capacity of the unit at the minimum compressor speed is greater than or equal to the building load. The unit cycles on and off.

$Q\left(t_{j}\right)=Q_{s s}^{k=1}(67)+\left[Q_{s s}^{k=1}(82)-Q_{s s}^{k=1}(67)\right] \cdot\left[t_{j}-67\right] / 15$

$E\left(t_{j}\right)=E_{s s}^{\mathrm{k}=1}(67)+\left[E_{s s}^{\mathrm{k}=1}(82)-E_{s ~ s}^{\mathrm{k}=1}(67)\right] \cdot\left[t_{j}-67\right] / 15$.

CASE II, $Q_{s s}^{k=1}\left(t_{j}\right)<B L\left(t_{j}\right)<Q_{s s}^{k=2}\left(t_{j}\right), \quad\left(t_{1}<t_{j}<t_{2}\right)$

The unit is able to match the building load by modulating compressor speed between the minimum $(k=1)$ and maximum $(k=2)$ speed.

$$
\begin{aligned}
& Q\left(t_{j}\right)=B L\left(t_{j}\right) \\
& E\left(t_{j}\right)=\frac{Q\left(t_{j}\right)}{\operatorname{EER}_{s s}^{k=v}\left(t_{j}\right)}
\end{aligned}
$$


where: $\operatorname{EER}_{s s}^{k=v}\left(t_{j}\right)=a+b \cdot t_{j}+c \cdot t_{j}^{2}$,

steady state energy efficiency ratio at temperature $t_{j}$ and at an intermediate speed at which the unit capacity matches the building load, (Btu/W.h)

$a, b, c=$ coefficients to be calculated

The following is a procedure for evaluation of coefficients $a, b$, and $c$. The unit performance has to be evaluated first at the compressor speed $(k=i)$ at which the intermediate speed test was conducted. The capacity of the unit at any temperature $t$ with the compressor operating at the intermediate speed $(k=i)$ shall be determined by:

$\underset{s s}{Q k=i}(t)=Q_{s s}^{k=i}(87)+M_{Q}[t-87]$

where: $Q_{s s}^{k=i}(87)=$ capacity of the unit at $87^{\circ} \mathrm{F}$ determined by the intermediate speed steady state test, (Btu/h)

$$
\begin{gathered}
M_{Q}=\frac{Q_{s s}^{k=1}(82)-Q_{s s}^{k=1}(67)}{82-67} \cdot\left(1-N_{Q}\right)+ \\
\frac{Q_{s ~ s}^{k=2}(95)-Q_{s ~ s}^{k=2}(82)}{95-82} \cdot N_{Q}
\end{gathered}
$$

$$
N_{Q}=\frac{Q_{s s}^{k=i}(87)-Q_{s s}^{k=1}(87)}{Q_{s s}^{k=2}(87)-Q_{s s}^{k=1}(87)}
$$


$\mathrm{Q}_{\mathrm{s} s}^{\mathrm{k}=1}(87)$ and $\mathrm{Q}_{\mathrm{s} s}^{\mathrm{k}=2}(87)$ shall be calculated by equations (3.9) and (3.28), respectively.

Once the equation (3.18) for $\mathrm{Q}_{\mathrm{s} s}^{\mathrm{k}=1}(t)$ has been determined, the temperature at which $\mathrm{Q}_{\mathrm{ss}}^{\mathrm{k}=\mathrm{i}}(t)=\mathrm{BL}(t)$ can be found. This temperature, designated as $t_{\mathrm{vc}}$, shall be calculated by the equation:

$t_{v c}=\frac{33 \cdot Q_{s s}^{k=i}(87)-2871 \cdot M_{Q}+65 \cdot Q_{s s}^{k=2}(95)}{Q_{s s}^{k=2}(95)-33 \cdot M_{Q}}$

The electrical power input for the unit operating at the intermediate compressor speed $(k=i)$ and the temperature $\left(t_{v c}\right)$ is determined by:

$\mathrm{E}_{\mathrm{ss}}^{\mathrm{k}=\mathrm{i}}\left(t_{\mathrm{vc}}\right)=\mathrm{E}_{\mathrm{ss}}^{\mathrm{k}=\mathrm{i}}(87)+\mathrm{M}_{\mathrm{E}}\left[t_{\mathrm{vc}}-87\right]$

where: $E_{\mathrm{ss}}^{\mathrm{k}=\mathrm{i}}(87)=$ electrical power input of the unit at $87^{\circ} \mathrm{F}$ determined by the intermediate speed, steady state test, (W)

$$
\begin{aligned}
M_{E}= & \frac{E_{s s}^{k=1}(82)-E_{s ~}^{k=1}(67)}{82-67} \cdot\left[1-N_{E}\right] \\
+ & \frac{E_{s ~}^{k=2}(95)-E_{s ~ s}^{k=2}(82)}{95-82} \cdot N_{E} \\
N_{E}= & \frac{E_{s s}^{k=1}(87)-E_{s s}^{k=1}(87)}{E_{s ~}^{k=2}(87)-E_{s ~}^{k=1}(87)}
\end{aligned}
$$

$E_{S=1}^{k=1}(87)$ and $E_{S s}^{k=2}(87)$ shall be calculated by equations (3.14) and (3.33), respectively. 
The energy efficiency ratio of the unit, $\operatorname{EER}_{s}^{k}=1\left(t_{v c}\right)$, at the speed $(k=i)$ and temperature $t_{\mathrm{v}}$ shall be calculated by the equation:

$\operatorname{EER}_{s s}^{k=1}\left(t_{v c}\right)=\frac{Q_{s s}^{k=1}\left(t_{v c}\right)}{E_{s s}^{k=1}\left(t_{v c}\right)}$

Similarly, energy efficiency ratios at temperatures, $t_{1}$ and $t_{2}$ shall be calculated by the equations:

$$
\begin{aligned}
& \operatorname{EER}_{s s}^{k=1}\left(t_{1}\right)=\frac{Q_{s s}^{k=1}\left(t_{1}\right)}{E_{s s}^{k=1}\left(t_{1}\right)} \\
& \operatorname{EERs~}_{s=2}^{k=2}\left(t_{2}\right)=\frac{Q_{s s}^{k=2}\left(t_{2}\right)}{E_{s s}^{k=2}\left(t_{2}\right)}
\end{aligned}
$$

where: $\operatorname{EER}_{\mathrm{s} s}^{\mathrm{k}=1}\left(t_{1}\right)=$ steady state energy efficiency ratio at the minimum compressor speed at temperature $t_{1},(B t u / W \cdot h)$

$$
\begin{aligned}
\operatorname{EER}_{\mathrm{ss}}^{\mathrm{k}=2}\left(t_{2}\right)= & \text { steady state energy efficiency radio at the maximum } \\
& \text { compressor speed at temperature } t_{2},(\mathrm{Btu} / \mathrm{W} \cdot \mathrm{h}) \\
\mathrm{Q}_{\mathrm{ss}}^{\mathrm{k}=1}\left(t_{1}\right)= & \mathrm{Q}\left(t_{1}\right), \text { steady state capacity at the minimum } \\
& \text { compressor speed at temperature } t_{1}, \text { calculated by } \\
& \text { eq. }(3.13),(\text { Btu/h) }
\end{aligned}
$$




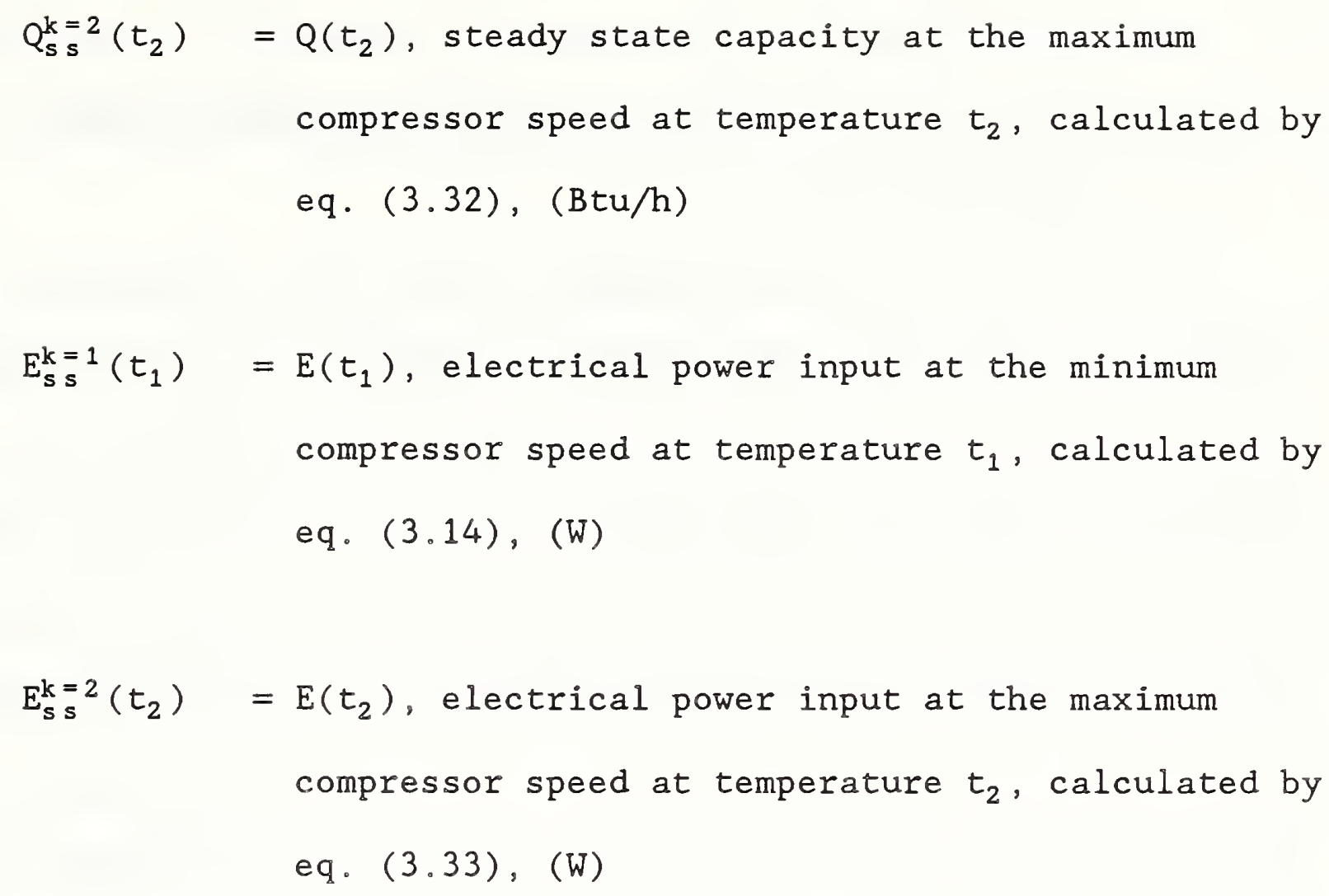

Finally, coefficients $a, b$, and $c$ shall be calculated using equations (3.28) through $(3.31)$ :

$d=\frac{t_{2}^{2}-t_{1}^{2}}{t_{v c}^{2}-t_{1}^{2}}$

$\mathrm{b}=\frac{\operatorname{EER}_{\mathrm{s} s}^{\mathrm{k}=1}\left(t_{1}\right)-\operatorname{EER}_{\mathrm{s} \mathrm{s}}^{\mathrm{k}=2}\left(t_{2}\right)-\mathrm{d} \cdot\left[\operatorname{EER}_{\mathrm{ss}}^{\mathrm{k}=1}\left(t_{1}\right)-\operatorname{EER}_{\mathrm{s} s}^{\mathrm{k}=\mathrm{i}}\left(t_{\mathrm{vc}}\right)\right]}{t_{1}-t_{2}-\mathrm{d} \cdot\left[t_{1}-t_{\mathrm{vc}}\right]}$

$c=\frac{\operatorname{EER}_{s \mathrm{~s}}^{\mathrm{k}=1}\left(t_{1}\right)-\mathrm{EER}_{\mathrm{s} s}^{\mathrm{k}=2}\left(t_{2}\right)-b \cdot\left[t_{1}-t_{2}\right]}{t_{1}^{2}-t_{2}^{2}}$

$a=\operatorname{EER}_{s \mathrm{~s}}^{\mathrm{k}=2}\left(t_{2}\right)-\mathrm{b} \cdot t_{2}-c \cdot t_{2}^{2}$ 
CASE III, $\quad B L\left(t_{j}\right) \geq Q_{s s}^{k=2}\left(t_{j}\right), \quad\left(t_{j} \geq t_{2}\right)$

Capacity of the unit at the maximum $(k=2)$ compressor speed is equal to or smaller than the building load.

$Q\left(t_{j}\right)=Q_{s s}^{k=2}(82)+\left[Q_{s s}^{k=2}(95)-Q_{s s}^{k=2}(82)\right]\left[t_{j}-82\right] / 13$

$E\left(t_{j}\right)=E_{s s}^{k=2}(82)+\left[E_{s s}^{k=2}(95)-E_{s s}^{k=2}(82)\right]\left[t_{j}-82\right] / 13$

4. RATING PROCEDURE FOR VARIABLE SPEED SYSTEMS IN THE HEATING MODE

4.1 Requirements for Testing Conditions and Testing Procedures Requirements regarding instruments and data acquisition systems, test apparatus, methods of test, test procedures, and data analysis are as prescribed in ASHRAE Standard 116-1983 [15] with the exception to the provisions specified in the following sections.

\subsubsection{Tests and Testing Conditions}

The tests and test conditions are presented in Table 3 .

\subsubsection{Cyclic Test}

The cyclic test shall be conducted according to provisions specified in section 3.1 .2 of this document and with the compressor time-on and timeoff specified for the cyclic test in the cooling mode. Results of the heating mode cyclic test shall be used with results of the maximum temperature heating test to evaluate the cyclic degradation coefficient, $C_{D}$, as specified in section 9.2.4 of ASHRAE Standard 116-1983 [15]. An 
assigned value of 0.25 may be used for the degradation coefficient, $C_{D}$, in lieu of conducting the heating cyclic test.

\subsubsection{Intermediate Speed Frost Accumulation Test}

The compressor speed shall be the same as during the intermediate speed test in the cooling mode. Compressor speed variations are allowed as specified in section 3.1.3. Also, variations associated with control strategies (if employed) during the initial period after switching from defrosting to heating, in the final period of the heating cycle, and during defrosting are permitted. Variations of the compressor speed from the prescribed speed are allowed to the same extent and for the same period of time as such variation would occur in the field due to control strategy.

\subsubsection{Maximum Speed Frost Accumulation Test}

In lieu of conducting the test the following equations may be used to obtain heat pump capacity and power at the test conditions:

$$
\begin{aligned}
& \mathrm{Q}_{\mathrm{d} \text { ef }}^{\mathrm{k}=2}(35)=0.90 \cdot\left[\mathrm{Q}_{\mathrm{d} \text { ef }}^{\mathrm{k}=2}(17)+\left[\mathrm{Q}_{\mathrm{def}}^{\mathrm{k}=2}(47)-\mathrm{Q}_{\mathrm{de}}^{\mathrm{k}=2}(17)\right][35-17] /[47-17]\right] \\
& \mathrm{E}_{\mathrm{def}}^{\mathrm{k}=2}(35)=0.985 \cdot\left[\mathrm{E}_{\mathrm{def}}^{\mathrm{k}=2}(17)+\left[\mathrm{E}_{\mathrm{def}}^{\mathrm{k}=2}(47)-\mathrm{E}_{\mathrm{def}}^{\mathrm{k}=2}(17)\right][35-17] /[47-17]\right]
\end{aligned}
$$

\subsubsection{Nominal Speed High Temperature Test}

This test is applicable if the maximum compressor speed in the heating mode is greater than the maximum speed in the cooling mode. In such a case the nominal speed is the maximum speed the compressor may run in the cooling mode. The heating capacity obtained during the nominal speed high 
temperature test shall be used only to calculate design heating requirements. This test is optional. If this test is not opted to be performed or is not applicable, capacity obtained during the maximum speed high temperature heating test shall be used for design heating requirement calculations.

\subsubsection{Air Quantity Measurement}

Air flow quantity and measurement method shall comply with provisions specified in section 3.1 .4 .

\subsubsection{Power Measurement}

Power measurement shall be performed as prescribed for the cooling mode in section 3.1 .5

\subsection{Calculation of Heating Seasonal Performance Factor, HSPF}

The Heating Seasonal Performance Factor, HSPF, shall be calculated by the following equation:

$H S P F=\frac{\sum_{j} n_{j} \cdot B L\left(t_{j}\right)}{\sum_{j} n_{j} \cdot\left[e\left(t_{j}\right)+R H\left(t_{j}\right)\right]}$

where: $t_{j}=$ representative outdoor dry-bulb temperature for temperature bin $\mathrm{j},\left({ }^{\circ} \mathrm{F}\right)$

$\mathrm{n}_{\mathrm{j}}=$ Eractional heating bin hours in bin $j$, per Table 4

$\operatorname{BL}\left(\tau_{j}\right)=$ building load at bin temperature $t_{j},(B t u / h)$ 


$$
\begin{aligned}
e\left(t_{j}\right)= & \text { power input to the system (excluding the supplemental } \\
& \text { resistance heater) operating in temperature } t_{j},(W) \\
R H\left(t_{j}\right)= & \text { power input to the supplementary resistance heater } \\
& \text { required in those cases when the heat pump automatically } \\
& \text { turns off }\left(t_{j}<t_{o n}\right) \text {, or when it is needed to meet the } \\
& \text { balance of the building heating requirement, (W) }
\end{aligned}
$$

The building load, $\mathrm{BL}\left(t_{j}\right)$, shall be calculated by the following equation:

$\operatorname{BL}\left(t_{j}\right)=\frac{65-t_{j}}{65-T_{D}} \cdot C \cdot D H R$

where: $\quad C=0.77$, an experience factor which improves the agreement between calculated and measured building loads, (-)

$\mathrm{T}_{\mathrm{D}}=$ outdoor design temperature (shown for different regions in Table 4$),\left({ }^{\circ} \mathrm{F}\right)$

DHR = design heating requirement, $(\mathrm{Btu} / \mathrm{h})$

The minimum and maximum design heating requirements, $\mathrm{DHR}_{\mathrm{m} i n}$ and $\mathrm{DHR}_{\mathrm{max}}$, of a residence in which a heat pump is likely to be installed shall be obtained by evaluating the following two equations and rounding off the results to the nearest standardized values given in Table 5 .

$$
\begin{aligned}
& \operatorname{DHR}_{\mathrm{min}}= \begin{cases}Q_{s s}^{\mathrm{k}=\mathrm{n}}(47) \cdot\left[65-\mathrm{T}_{\mathrm{D}}\right] / 60, & \text { for regions } \mathrm{I}, \mathrm{II}, \mathrm{III}, \mathrm{IV}, \text { and VI } \\
\mathrm{Q}_{\mathrm{ss}}^{\mathrm{k}=\mathrm{n}}(47), & \text { for region } \mathrm{V}\end{cases} \\
& \operatorname{DHR}_{\mathrm{max}}= \begin{cases}2 \cdot \mathrm{Q}_{\mathrm{ss}}^{\mathrm{k}=\mathrm{n}}(47)\left[65-\mathrm{T}_{\mathrm{D}}\right] / 60, & \text { for regions } \mathrm{I}, \mathrm{II}, \mathrm{III,} \text { IV and VI } \\
2.2 \circ \mathrm{Q}_{\mathrm{ss}}^{\mathrm{k}=\mathrm{n}}(47), & \text { for region } \mathrm{V}\end{cases}
\end{aligned}
$$


where:

$$
Q_{s s}^{k=n}(47)=\left\{\begin{array}{l}
\text { system capacity during the optional nominal speed high } \\
\text { temperature test } \\
Q_{s s}^{k=2}(47) \text { if the nominal speed high temperature test } \\
\text { was not performed, (Btu/h) }
\end{array}\right.
$$

The quantities $e\left(t_{j}\right)$ and $\mathrm{RH}\left(t_{j}\right)$ shall be calculated by the following equations:

$e\left(t_{j}\right)=\frac{\delta\left(t_{j}\right) \cdot X\left(t_{j}\right) \cdot E\left(t_{j}\right)}{\operatorname{PLF}(X)}$

$R H\left(t_{j}\right)=\frac{B L\left(t_{j}\right)-\delta\left(t_{j}\right) \cdot X\left(t_{j}\right) \cdot Q\left(t_{j}\right)}{3.413}$

where: $\delta\left(t_{j}\right)=$ heat pump low temperature cut-off factor, (-)

$$
\begin{aligned}
& \delta\left(t_{j}\right)=\left\{\begin{array}{l}
0 \text { if } t_{j} \leq t_{\text {off }} \text { or } Q\left(t_{j}\right) /\left(3.413 \cdot E\left(t_{j}\right)\right)<1 \\
0.5 \text { if } t_{\text {off }}<t_{j} \leq t_{\text {on }} \text { and } Q\left(t_{j}\right) /\left(3.413 \cdot E\left(t_{j}\right)\right) \geq 1 \\
1 \text { if } t_{j}>t_{\text {on }} \text { and } Q\left(t_{j}\right) /\left(3.413 \cdot E\left(t_{j}\right)\right) \geq 1
\end{array}\right. \\
& t_{\mathrm{O} f}=\text { outdoor temperature at which the compressor is } \\
& \text { automatically stopped to avoid operation at low temperatures } \\
& t_{\mathrm{on}}=\text { outdoor temperature at which the compressor is } \\
& \text { automatically turned on after low-temperature shut-off } \\
& X\left(t_{j}\right)=\text { heating load factor, }(-) \\
& X\left(t_{j}\right)=\left\{\begin{array}{l}
B L\left(t_{j}\right) / Q\left(t_{j}\right) \text { if } B L\left(t_{j}\right) / Q\left(t_{j}\right)<1 \\
1 \text { otherwise }
\end{array}\right.
\end{aligned}
$$




$$
\begin{aligned}
\operatorname{PLF}(\mathrm{X})= & \text { part load factor } \\
\mathrm{PLF}(\mathrm{X})= & 1-\mathrm{C}_{\mathrm{D}}\left[1-\mathrm{X}\left(\mathrm{t}_{\mathrm{j}}\right)\right] \\
\mathrm{C}_{\mathrm{D}}= & \text { cyclic degradation coefficient, (-) } \\
\mathrm{Q}\left(\mathrm{t}_{\mathrm{j}}\right)= & \text { system capacity at temperature } t_{j} \text { during continuous } \\
& \text { compressor operation at the speed needed to match the } \\
& \text { building load, (Btu/h) } \\
\mathrm{E}\left(t_{j}\right)= & \text { power input to the system at temperature } t_{j} \text { (excluding } \\
& \text { the supplemental resistance heater) during continuous } \\
& \text { compressor operation at the speed needed to match the } \\
& \text { building load, (W) }
\end{aligned}
$$

Quantities $Q\left(t_{j}\right)$ and $E\left(t_{j}\right)$ shäl be calculated according to three possible cases depending on compressor operation, as shown in Figure 10. These three cases can be identified in terms of the three outdoor temperature ranges or the two temperatures, $t_{3}$ and $t_{4}$, which separate them.

The outdoor temperature, $t_{3}$, at which the building load equals system capacity with the compressor operating at the minimum ( $k=1$ ) speed shall be calculated by the equation:

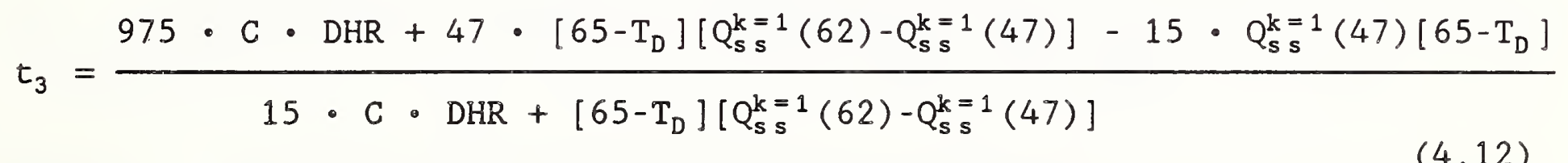




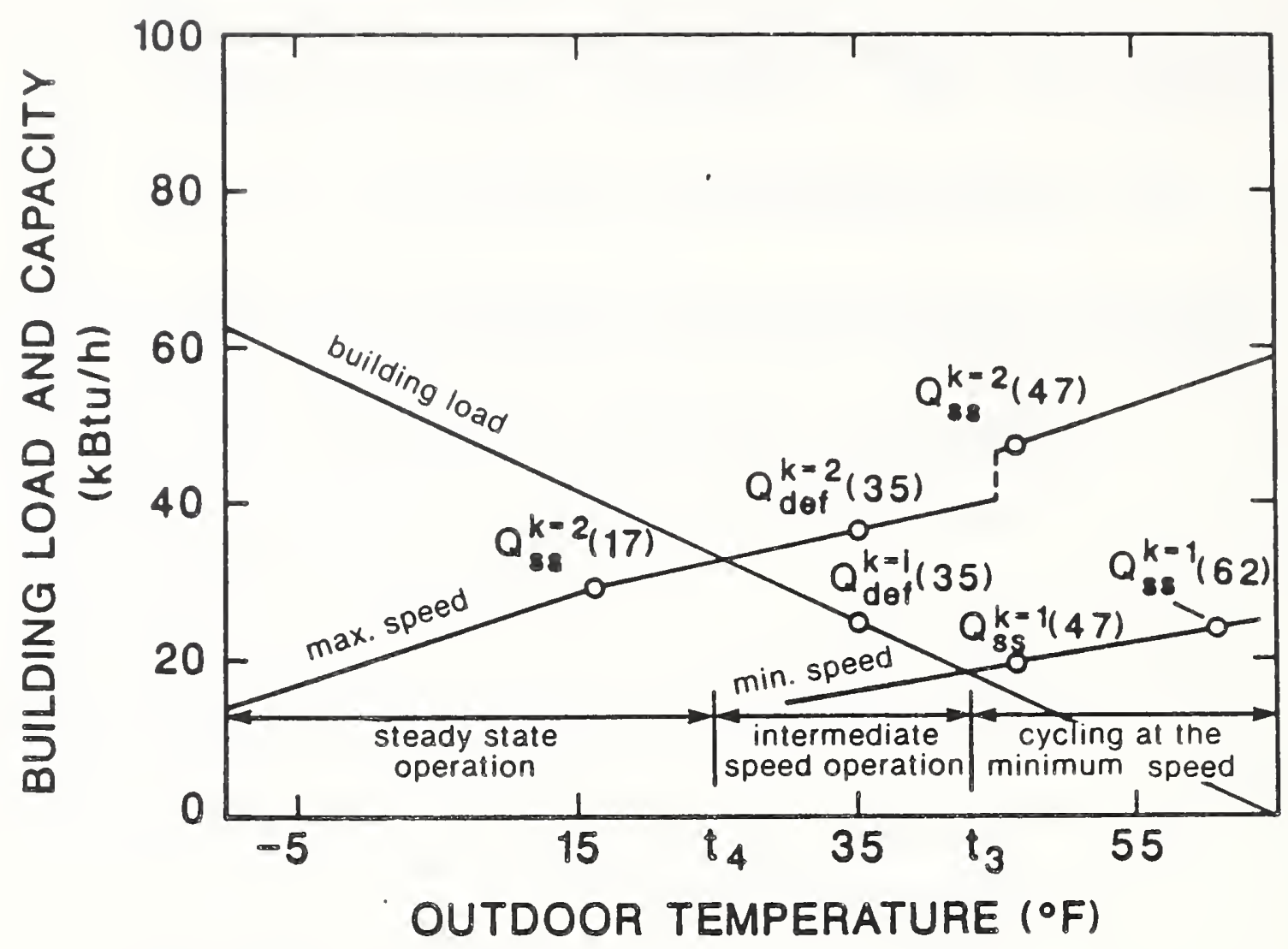

Figure 10. Building heating load and capacity of a variable speed heat pump.

The outdoor temperature, $t_{4}$, at which the building load equals system capacity with the compressor operating at the maximum speed $(k=2)$ shall be calculated by either equation ( 4.13 ) or (4.14), as appropriate:

If the calculated value for $t_{4}$ is smaller than or equal to 17 :

$t_{4}=\frac{1.950 \cdot C \cdot D H R+17\left[65-T_{D}\right]\left[Q_{s s}^{k=2}(47)-Q_{s s}^{k=2}(17)\right]-30 \cdot Q_{s s}^{k=2}(17)\left[65-T_{D}\right]}{30 \cdot C \cdot D H R+\left[65-T_{D}\right]\left[Q_{s s}^{k=2}(47)-Q_{s s}^{k=2}(17)\right]}$

If the calculated value for $t_{4}$ is greater than $17, t_{4}$ shall be calculated by the following equation: 


$$
t_{4}=\frac{1170 \cdot C \cdot D H R+17\left[65-T_{D}\right]\left[Q_{d e f}^{k=2}(35)-Q_{s s}^{k=2}(17)\right]-18 Q_{s s}^{k=2}(17)\left[65-T_{D}\right]}{18 \cdot C \cdot D H R+\left[65-T_{D}\right]\left[Q_{d e f}^{k=2}(35)-Q_{s s}^{k=2}(17)\right]}
$$

The equations for $t_{3}$ and $t_{4}$ were derived by equating the building load (eq. (4.4)) with respective system capacities and the minimum and maximum speeds (eq. (4.15) and eq. (4.34) or (4.36)).

CASE I, $\quad Q_{s s}^{k=1}\left(t_{j}\right) \geq B L\left(t_{j}\right), \quad\left(t_{j} \geq t_{3}\right)$

Capacity of the unit at the minimum compressor speed $(k=1)$ is greater than or equal to the building load. The unit cycles on and off.

$Q\left(t_{j}\right)=Q_{s s}^{k=1}(47)+\left[Q_{s s}^{k=1}(62)-Q_{s s}^{k=1}(47)\right]\left[t_{j}-47\right] / 15$

$E\left(t_{j}\right)=E_{s s}^{k=1}(47)+\left[E_{s s}^{k=1}(62)-E_{s s}^{k=1}(47)\right]\left[t_{j}-47\right] / 15$.

CASE II, $\quad Q_{s s}^{k=1}\left(t_{j}\right)<B L\left(t_{j}\right)<Q^{k=2}\left(t_{j}\right), \quad\left(t_{4}<t_{j}<t_{3}\right)$

The unit is able to match the building load by modulating compressor speed between the minimum ( $k=1$ ) and maximum ( $k=2)$ speed.

$Q\left(t_{j}\right)=B L\left(t_{j}\right)$

$E\left(t_{j}\right)=Q\left(t_{j}\right) /\left(3.413 \cdot \operatorname{COP}^{k}=v\left(t_{j}\right)\right)$

where: $\quad \operatorname{COP}^{\mathrm{k}=\mathrm{v}}\left(t_{\mathrm{j}}\right)=$ coefficient of performance at an intermediate speed at which the unit delivers capacity matching the building load at temperature $t_{j}$ 


$$
\operatorname{COP}^{\mathrm{k}=\mathrm{v}}\left(t_{\mathrm{j}}\right)=a+b \cdot t_{j}+c \cdot t_{j}^{2}
$$

$\mathrm{a}, \mathrm{b}, \mathrm{c}=$ coefficients which have to be calculated separately for each design building requirement

The following is a procedure for evaluation of coefficients $a, b$, and $c$.

Before the coefficient of performance, $\operatorname{COP}^{\mathrm{k}=\mathrm{v}}\left(t_{j}\right)$, can be calculated, the unit performance has to be evaluated at the compressor speed $(k=i)$ at which the intermediate speed test was conducted. The capacity of the unit at any temperature $t$ when the compressor operates at the intermediate speed $(k=i)$ shall be determined by:

$Q_{d e f}^{k=i}(t)=Q_{d e f}^{k=i}(35)+M_{Q}[t-35]$

where: $Q_{d e f}^{k=i}(35)=$ capacity of the unit at $35^{\circ} \mathrm{F}$ determined at the intermediate compressor speed $(k=i)$ in the frost accumulation test, (Btu/h)

$$
\mathbb{M}_{Q}=\frac{Q_{s s}^{k=1}(62)-Q_{s s}^{k=1}(47)}{62-47} \cdot\left(1-N_{Q}\right)
$$

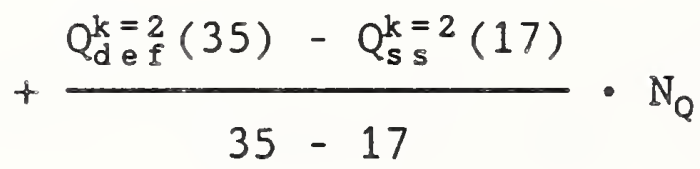

$$
\mathbb{N}_{Q}=\frac{Q_{d e f}^{k=1}(35)-Q^{k=1}(35)}{Q_{d e f}^{k=2}(35)-Q^{k=1}(35)}
$$




$$
\begin{aligned}
& \mathrm{Q}^{\mathrm{k}=1}(35)=\mathrm{Q}(35) \text {, capacity of the unit at } 35^{\circ} \mathrm{F} \text { at the minimum } \\
& \text { compressor speed, calculated by equation }(4.15),(\mathrm{Btu} / \mathrm{h})
\end{aligned}
$$

Once the equation for $\underset{d e f}{\mathrm{k}=i}(t)$ has been determined, the temperature at which $\mathrm{Q}_{\mathrm{def}}^{\mathrm{k}=\mathrm{i}}(t)=\mathrm{BL}(t)$ can be found. This temperature, designated as $t_{\mathrm{vh}}$, shall be calculated by the equation:

$t_{v h}=\frac{65 \cdot C \cdot D H R+\left[65-T_{D}\right]\left[35 \cdot \mathrm{M}_{Q}-Q_{d e f}^{k=i}(35)\right]}{C \cdot D H R+M_{Q}\left[65-T_{D}\right]}$

A separate $t_{v h}$ shall be determined for each design heating requirement.

The electrical power input for the unit operating at the intermediate compressor speed $(k=i)$ and at the temperature $t_{v h}$ shall be determined by:

$E_{d e f}^{k=i}\left(t_{v h}\right)=E_{d e f}^{k=i}(35)+M_{E}\left[t_{v h}-35\right]$

where: $\quad E_{\mathrm{d} e f}^{\mathrm{k}}=\mathrm{i}(35)=$ electrical power input of the unit at $35^{\circ} \mathrm{F}$ determined at the intermediate compressor speed $(k=i)$ in the frost accumulation test, (W)

$$
M_{E}=\frac{E_{s ~ s}^{k=1}(62)-E_{s ~ s}^{k=1}(47)}{62-47} \cdot\left(1-N_{E}\right)
$$

$$
+\frac{E_{d e f}^{\mathrm{k}=2}(35)-E_{\mathrm{s} \mathrm{s}}^{\mathrm{k}=2}(17)}{35-17} \cdot \mathrm{N}_{E}
$$




$$
N_{E}=\frac{E_{d e f}^{k=i}(35)-E^{k=1}(35)}{E_{d e f}^{k=i}(35)-E^{k=1}(35)}
$$

The coefficient of performance, $\operatorname{COP}_{\mathrm{d} e f}^{k=i}\left(t_{v h}\right)$, at the intermediate speed $(k=i)$ and temperature $t_{v h}$ shall be calculated by the equation:

$$
c_{0} P_{d e f}^{k=i}\left(t_{v h}\right)=\frac{Q_{d e f}^{k=i}\left(t_{v h}\right)}{3.413 \cdot E_{d e f}^{k=i}\left(t_{v h}\right)}
$$

Similarly, coefficients of performance at temperature $t_{3}$ and $t_{4}$ shall be calculated by the equations:

$$
\begin{aligned}
& \operatorname{COP}^{\mathrm{k}=1}\left(t_{3}\right)=\frac{\mathrm{Q}^{\mathrm{k}=1}\left(t_{3}\right)}{3.413: \mathrm{E}^{\mathrm{k}=1}\left(t_{3}\right)} \\
& \operatorname{COP}^{\mathrm{k}=2}\left(t_{4}\right)=\frac{\mathrm{Q}^{\mathrm{k}=2}\left(t_{4}\right)}{3.413 \cdot \mathrm{E}^{\mathrm{k}=2}\left(t_{4}\right)}
\end{aligned}
$$

where: $\operatorname{cop}^{\mathrm{k}=1}\left(t_{3}\right)=$ coefficient of performance at the minimum compressor speed at temperature $t_{3},(-)$

$$
\begin{aligned}
\operatorname{COP}^{\mathrm{k}=2}\left(t_{4}\right)= & \text { coefficient of performance at the maximum compressor } \\
& \text { speed at temperature } t_{4},(-) \\
\mathrm{Q}^{\mathrm{k}=1}\left(t_{3}\right)= & \mathrm{Q}\left(t_{3}\right), \text { system capacity at the minimum compressor } \\
& \text { speed at temperature } t_{3}, \text { calculated by eq. (4.15), (Btu/h) }
\end{aligned}
$$




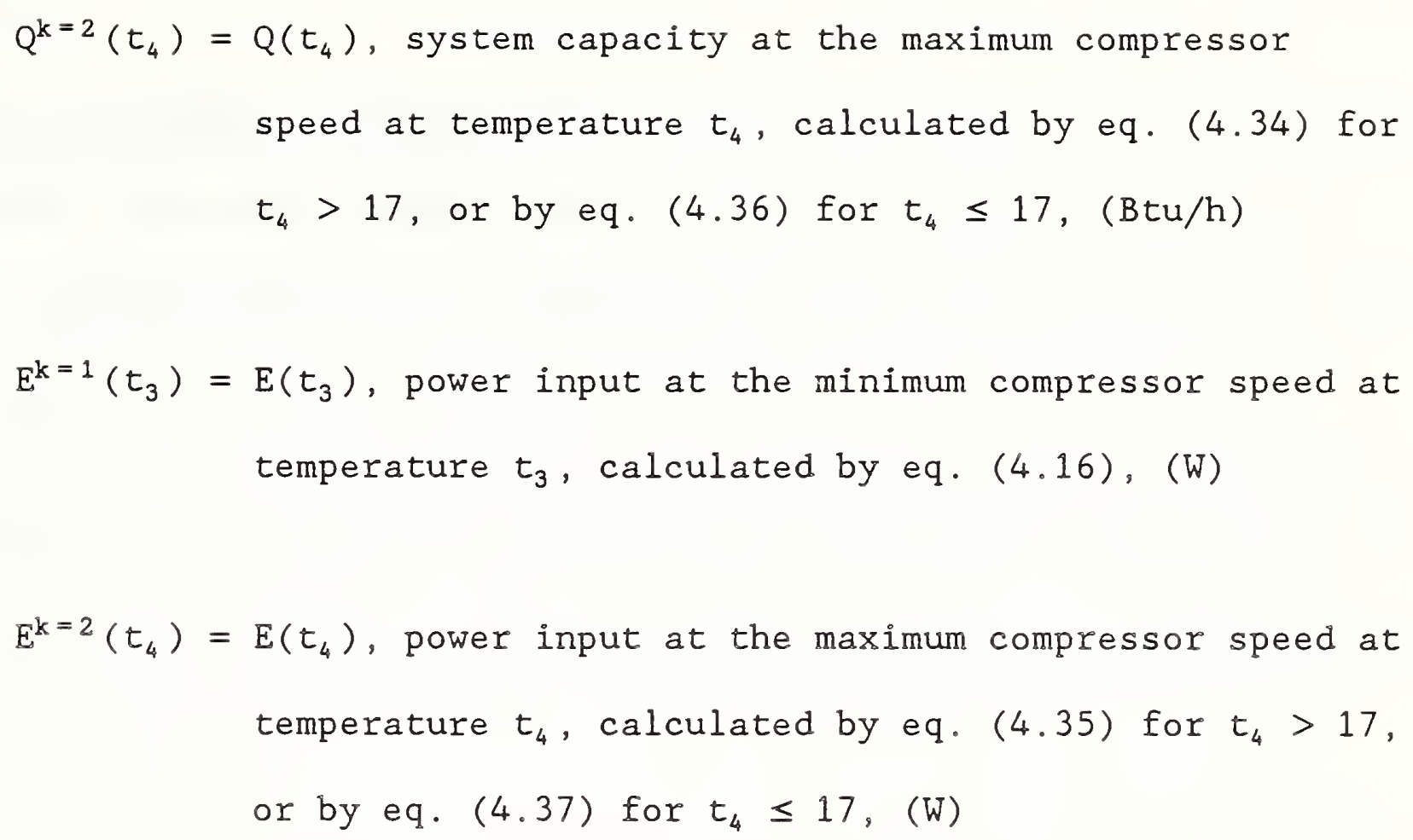

Finally, coefficients $a, b$, and $c$ shall be calculated using equations (4.30) through $(4.33)$ :

$d=\frac{t_{3}^{2}-t_{4}^{2}}{t_{v h}^{2}-t_{4}^{2}}$

$\mathrm{b}=\frac{\operatorname{COP}^{\mathrm{k}=2}\left(t_{4}\right)-\operatorname{COP}^{\mathrm{k}=1}\left(t_{3}\right)-\mathrm{d} \cdot\left[\operatorname{COP}^{\mathrm{k}=2}\left(t_{4}\right)-\operatorname{COP}_{\mathrm{def}}^{\mathrm{k}=1}\left(t_{\mathrm{vh}}\right)\right]}{t_{4}-t_{3}-\mathrm{d} \cdot\left[t_{4}-t_{\mathrm{vh}}\right]}$

$c=\frac{\operatorname{COP}^{\mathrm{k}=2}\left(t_{4}\right)-\operatorname{COP}^{\mathrm{k}=1}\left(t_{3}\right)-b \cdot\left[t_{4}-t_{3}\right]}{t_{4}^{2}-t_{3}^{2}}$

$a=\operatorname{cop}^{\mathrm{k}=2}\left(t_{4}\right)-b \cdot t_{4}-c \cdot t_{4}^{2}$ 
CASE III, $\quad \operatorname{BL}\left(t_{j}\right) \geq Q^{k=2}\left(t_{j}\right), \quad\left(t_{j} \leq t_{4}\right)$

Capacity of the system at the maximum $(k=2)$ compressor speed is equal to or less than the building load. Evaluation of $Q\left(t_{j}\right)$ and $E\left(t_{j}\right)$ depends on the value of $t_{j}$ as prescribed in equations (4.34) through (4.37).

$$
\begin{aligned}
& \text { If } t_{j} \geq 17^{\circ} \mathrm{F} \\
& Q\left(t_{j}\right)=Q_{s s}^{k=2}(17)+\left[Q_{d e f}^{k=2}(35)-Q_{s s}^{k=2}(17)\right]\left[t_{j}-17\right] / 18 \\
& E\left(t_{j}\right)=E_{s s}^{k=2}(17)=\left[E_{s s}^{k=2}(35)-E_{s s}^{k=2}(17)\right]\left[t_{j}-17\right] / 18
\end{aligned}
$$

$$
\begin{aligned}
& \text { If } t_{j}<17^{\circ} \mathrm{F} \\
& Q\left(t_{j}\right)=Q_{s s}^{k=2}(17)+\left[Q_{s s}^{k=2}(47)-Q_{s s}^{k=2}(17)\right]\left[t_{j}-17\right] / 30 \\
& E\left(t_{j}\right)=E_{s s}^{k=2}(17)+\left[E_{s s}^{k=2}(47)-E_{s s}^{k=2}(17)\right]\left[\tau_{j}-17\right] / 30
\end{aligned}
$$




\section{REFERENCES}

1. Federal Register, Test Procedures for Central Air Conditioners, Including Heat Pumps, Vol. 44, No. 249, p. 76700, U.S. Government Printing Office, Washington, DC, December 27, 1979.

2. Federal Register, Proposed Rulemaking and Public Hearing Regarding Test Procedures for Central Air Conditioners, Including Heat Pumps, Vol. 51, No. 194, p. 35736, U.S. Government Printing Office, Washington, DC, October 7, 1986.

3. Borg-Warner Corporation, Application for Exception from Central Air Conditioner Test Procedures, DoE Office of Hearings and Appeals, Case BEE-1338, January 13, 1981.

4. Air Conditioning and Refrigeration Institute, Standard 210/240 for Unitary Air-Conditioning and Air-source Heat Pump Equipment, Arlington, VA, 1984.

5. Urbs, D.G., Bullock, C.E. and Voorhis, R.J., New Testing and Rating Procedures for Seasonal Performance of Heat Pumps with Variable Speed Compressors, ASHRAE Transactions, Vol. 92, Part 2, 1986.

6. Federal Register, Petition for Waiver of Central Air Conditioner Test Procedures from Carrier Corporation, (Case CAC-001), Vol. 51, No. 31, p. 5587, U.S. Government Printing Office, Washington, DC, February 14, 1986.

7. Federal Register, Petition for Waiver of Central Air Conditioner Test Procedures from The Trane Co., (Case CAC-002), Vol. 51, No. 192, p. 35410, U.S. Government Printing Office, Washington, DC, October 3, 1986.

8. Horak, B.F., of ETL Testing Laboratories, Cortland, NY, letter of June 3, 1987.

9. Mohan, N. and Ramsey, J.W., Comparative Study of Adjustable-Speed Drives for Heat Pumps, Electric Power Research Institute, EM-4704, Palo Alto, CA, 1986.

10. Baldwin, A.J., Planer, N.G., Nordell, D.E. and Mohan, N., Evaluation of Electrical Interference to the Induction Watthour Meter, Electric Research Power Institute, EL-2315, Palo Alto, CA, 1982.

11. Miller, W.A. of Oak Ridge National Laboratory, Oak Ridge, TN, private communication, April, 1987.

12: Urbs, D.G. of Carrier Corporation, Syracuse, NY, private communication, June, 1987.

13. Kirkpatrick, K. of Trane Co., Tyler, TX, private communication, June, 1987. 
14. Nelson, L.W. of Honeywell Inc., Golden Valley, MN, private communication, July, 1987.

15. The American Society of Heating, Refrigerating, and Air-Conditioning Engineers, Inc., ANSI/ASHRAE Standard 116-1983, Atlanta, GA, 1983. 
APPENDIX A. EXAMPLE OF SEER CALCULATION

This appendix contains an example of calculations required for determination of the Seasonal Energy Efficiency Ratio, SEER.

Table A1 presents a summary of calculations performed for each temperature bin. Calculation steps required for the $92^{\circ} \mathrm{F}$ temperature bin are shown in detail below.

The unit performance data needed by the calculation procedure are listed below:

$$
\begin{aligned}
& \mathrm{Q}_{\mathrm{ss}}^{\mathrm{k}=2}(95)=27000 \mathrm{Btu} / \mathrm{h} \quad \mathrm{E}_{\mathrm{ss}}^{\mathrm{k}=2}(95)=3288 \mathrm{~W} \\
& \mathrm{Q}_{\mathrm{s} \mathrm{s}}^{\mathrm{K}=2}(82)=28397 \mathrm{Btu} / \mathrm{h} \quad \mathrm{E}_{\mathrm{s} \mathrm{s}}^{\mathrm{K}=2}(82)=3082 \mathrm{~W} \\
& \mathrm{Q}_{\mathrm{s} s}^{\mathrm{k}=1}(82)=13130 \mathrm{Btu} / \mathrm{h} \quad \mathrm{E}_{\mathrm{s} \mathrm{s}}^{\mathrm{k}=1}(82)=958 \mathrm{~W} \\
& Q_{s s}^{k=1}(67)=14492 \quad \mathrm{Btu} / \mathrm{h} \quad \mathrm{E}_{\mathrm{s} \mathrm{s}}^{\mathrm{k}=1}(67)=859 \mathrm{~W}
\end{aligned}
$$

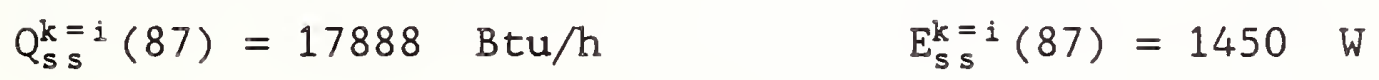

$$
\begin{aligned}
& C_{D}=0.2
\end{aligned}
$$

Step 1. Determine the minimum and maximum speed balance points, $t_{1}$ and $t_{2}$.

$t_{1}=\frac{975 \cdot 27000+495 \cdot 14492+2211 \cdot(14492-13130)}{15 \cdot 27000+33 \cdot(14492-13130)}=81.14^{\circ} \mathrm{F}$

$t_{2}=\frac{845 \cdot 27000+429 \cdot 28397+2706 \cdot(28397-27000)}{33 \cdot 28397-20 \cdot 27000}=97.65^{\circ} \mathrm{F}$

Since $t_{j}=92, \quad t_{1}<t_{j}<t_{2}$, Case II applies 
Step 2. Calculate $t_{\mathrm{v}}$.

$$
\begin{aligned}
& \mathrm{Q}_{\mathrm{s} \mathrm{s}}^{\mathrm{k}=1}(87)=14492+(13130-14492)(87-67) / 15=12676.0 \mathrm{Btu} / \mathrm{h} \quad(\mathrm{eq} \cdot(3.13)) \\
& \mathrm{Q}_{\mathrm{s} \mathrm{s}}^{\mathrm{k}=2}(87)=28397+(27000-28397)(87-82) / 13=27859.7 \mathrm{Btu} / \mathrm{h} \quad(\text { eq. (3.32)) } \\
& N_{Q}=\frac{17888-12676}{27859.7-12676}=0.34326 \\
& \text { (eq. }(3.20)) \\
& M_{Q}=\frac{13130-14492}{82-67} \cdot(1-034326)+ \\
& \frac{27000-28397}{95-82} \cdot 0.34326=-96.519 \\
& (\mathrm{eq} \cdot(3.19)) \\
& t_{v c}=\frac{33 \cdot 17888-2871 \cdot(-96.519)+65.27000}{27000-33 \cdot(-96.519)}=86.88^{\circ} \mathrm{F} \quad(\text { eq. }(3.21))
\end{aligned}
$$

Step 3. Calculate power at temperature $t_{\mathrm{vc}}$.

$$
\begin{aligned}
& \mathrm{E}_{\mathrm{SS}}^{\mathrm{k}=1}(87)=859+(958-859)(87-67) / 15=991.0 \mathrm{~W} \\
& \mathrm{E}_{\mathrm{S} \mathrm{S}}^{\mathrm{K}=2}(87)=3082+(3288-3082)(87-82) / 13=3161.2 \mathrm{~W} \\
& \mathrm{~N}_{\mathrm{E}}=\frac{1450-991}{3161.2-991}=0.21150 \\
& \mathrm{M}_{\mathrm{E}}=\frac{958-859}{82-67}(1 .-0.21150)+\frac{3288-3082}{95-82} \cdot 0.21150=8.556
\end{aligned}
$$

$$
E_{S S}^{\mathrm{k}=\mathrm{i}}(86.88)=1450 \cdot 8.556 \cdot(86.88-87.0)=1451.0 \mathrm{~W} \quad(\mathrm{eq} \cdot(3.22))
$$


Step 4. Calculate EER at temperatures $t_{1}=81.14, t_{\mathrm{vc}}=86.88$, and $t_{2}=97.65$.

$$
\begin{aligned}
& \mathrm{Q}_{\mathrm{s} \mathrm{s}}^{\mathrm{k}=1}(81.14)=14492+(13130-14492)(81.14-67) / 15=13208.1 \mathrm{Btu} / \mathrm{h} \\
& E_{s=1}^{k=1}(81.14)=859+(958-859)(81.1-67.0) / 15=952.1 \mathrm{~W} \quad \text { (eq. (3.14)) } \\
& \operatorname{EER}_{s s}^{\mathrm{k}=1}(81.14)=13208.1 / 952.1=13.87 \mathrm{Btu} /(\mathrm{W} \cdot \mathrm{h}) \quad \text { (eq. (3.26)) } \\
& \mathrm{Q}_{\mathrm{S} \mathrm{S}}^{\mathrm{k}=\mathrm{i}}(86.88)=\mathrm{BL}(86.88)=27000 \cdot(86.88-65) /(1.1 \cdot 30)=17901.8 \mathrm{Btu} / \mathrm{h} \\
& \text { (eq. }(3.5) \text { ) } \\
& E_{s s}^{k=i}(86.88)=1451.0 W \\
& \text { (step 3) }
\end{aligned}
$$

$$
\begin{aligned}
& \left.\operatorname{EER}_{\text {S s }}^{\mathrm{k}=i}(86.88)=\frac{17901.8}{1451.0}=12.34 \mathrm{Btu} /(\mathrm{W} \cdot \mathrm{h}) \quad \text { (eq. }(3.25)\right) \\
& \mathrm{Q}_{\mathrm{s} s}^{\mathrm{k}=2}(97.65)=28397+(27000-28397)(97.65-82) / 13=26715.2 \mathrm{Btu} / \mathrm{h} \\
& \text { (eq. }(3.32)) \\
& E_{s s}^{\mathrm{k}=2}(97.65)=3082+(3288-3082)(97.65-82) / 13=3330.0 \mathrm{~W} \quad(\text { eq. }(3.33)) \\
& \operatorname{EER}_{s s}^{\mathrm{k}=2}(97.65)=26715.2 / 3330.0=8.02 \mathrm{Btu} /(\mathrm{W} \cdot \mathrm{h}) \quad(\mathrm{eq} \cdot(3.27))
\end{aligned}
$$

Step 5. Evaluate parameters for a parabolic fit.

$$
\begin{aligned}
& \mathrm{d}=\left(97.65^{2}-81.14^{2}\right) /\left(86.88^{2}-81.14^{2}\right)=3.0607 \\
& \mathrm{~b}=\frac{13.87-8.02-3.0607 \cdot(13.87-12.34)}{81.14-97.65-3.0607 \cdot(81.14-86.88)}=1.1027 \\
& \mathrm{c}=\frac{13.87-8.02-1.1027 \cdot(81.14-97.65)}{81.14^{2}-97.65^{2}}=-8.1494 \cdot 10^{-3} \quad(\text { eq. }(3.29)) \\
& \left.a=8.02-1.1027 \cdot 97.65-\left(-8.1494 \cdot 10^{-3}\right) \cdot 97.65^{2}=-21.950 \quad(3.30)\right)
\end{aligned}
$$


Step 6. Calculate capacity and energy input at $92^{\circ} \mathrm{F}$ temperature.

$$
\begin{aligned}
& \mathrm{Q}(92)=\mathrm{BL}(92)=27000(92-65) / 33=22090.9 \quad \mathrm{Btu} / \mathrm{h} \\
& \mathrm{EER}_{\mathrm{s} \mathrm{s}}^{\mathrm{k}=\mathrm{v}}(92)=-21.950+1.1027 \cdot 92-8.1494 \cdot 10^{-3} \cdot 92^{2}=10.52 \quad \begin{array}{l}
\text { Btu } /(\mathrm{W} \cdot \mathrm{h}) \\
(\text { eq. }(3.17))
\end{array} \\
& \mathrm{E}(92)=\frac{22090.9}{10.52}=2099.9 \mathrm{~W}
\end{aligned}
$$

Step 7. Calculate seasonally weighted capacity and energy input at $92^{\circ} \mathrm{F}$ temperature bin.

$X(92)=1$

$\operatorname{PLF}(1)=1$

$(\mathrm{eq} \cdot(3.10))$

$q(92)=1 \cdot 22090.9=22090.9 \mathrm{Btu} / \mathrm{h}$

$($ eq. $(3.7))$

$\mathrm{n}_{6}=0.052$

(Table 2)

$\mathrm{n}_{6} \cdot \mathrm{q}(92)=0.052 \cdot 22090.9=1148.7 \mathrm{Btu} / \mathrm{h}$

$(\operatorname{eq} \cdot(3.6))$

$e(92)=1 \cdot 2099.9 / 1=2099.9 \mathrm{~W}$

$n_{6} \cdot e(92)=0.052 \cdot 2099.9=109.2 W$

$($ eq. $(3.6))$ 
It should be noted that some values in the above example differ from the respective values shown in Table Al due to smaller number of carried digits and the round-off error of hand-done calculations.

While performing calculations for all temperature bins, steps 1 through 5 have to be followed one time. Once coefficients $a, b$ and $c$ are evaluated, calculations for Case II start at Step 6. 
APPENDIX B. EXAMPLE OF HSPF CALCULATIONS

Example of HSPF Calculations.

This section contains an example of calculations required for determination of the Heating Seasonal Performance Factor, HSPF. The example calculations were performed for the minimum design heating requirement in region IV. The following are the unit performance data needed for calculating HSPF:

\begin{tabular}{|c|c|c|c|c|}
\hline$Q_{s ~ s}^{k=2}(47)$ & $=30838$ & Btu/h & $E_{s ~ s}^{k=2}(47)$ & $=3236$ \\
\hline$Q_{d e f}^{k=2}(35)$ & $=22930$ & Btu/h & $E_{\mathrm{def}}^{\mathrm{k}=2}(35)$ & $=2900$ \\
\hline$Q_{s ~ s}^{k=2}(17)$ & $=17112$ & Btu/h & $\mathrm{E}_{\mathrm{s}}^{\mathrm{k}=2}(17)$ & $=2544$ \\
\hline$Q_{s=1}^{k=1}(62)$ & $=13274$ & $\mathrm{Btu} / \mathrm{h}$ & $\mathrm{E}_{\mathrm{s} s}^{\mathrm{k}=1}(62)$ & $=1101$ \\
\hline$Q_{s s}^{k=1}(47)$ & $=10355$ & Btu $/ \mathrm{h}$ & $\mathrm{E}_{\mathrm{s} \mathrm{s}}^{\mathrm{k}=1}(47)$ & $=960$ \\
\hline$Q_{d \in f}^{k=i}(35)$ & $=10233$ & Btu $/ \mathrm{h}$ & $\mathrm{E}_{\mathrm{d}}^{\mathrm{k}=\mathrm{n}}(35)$ & $=1106$ \\
\hline$Q_{s=n}^{k=n}(47)$ & $=25670$ & Btu/h & & \\
\hline$C_{D}=0$ & & & & \\
\hline
\end{tabular}

First, the minimum and maximum heating requirements have to be determined. Since the nominal speed test was performed, capacity from this test, $\mathrm{Q}_{\mathrm{s} s}^{\mathrm{k}=\mathrm{n}}(47)$, will be used in calculations. For region IV after rounding off to the standardized values we obtain:

$\begin{array}{ll}\mathrm{DHR}_{\text {min }}=25670 \cdot(65-5) / 60=25670 \approx 25000 \mathrm{Btu} / \mathrm{h} & \begin{array}{l}(\text { eq. } \\ \text { and Table 5) }\end{array} \\ \mathrm{DHR}_{\text {max }}=50000 \mathrm{Btu} / \mathrm{h} & \\ & \begin{array}{l}\text { (eq. } \cdot(4.6) \\ \text { and Table 5) }\end{array}\end{array}$ 
Table B1 presents a summary of calculations performed for each temperature bin for minimum heating design requirement. Calculation steps required for $27^{\circ} \mathrm{F}$ temperature bin are shown in detail below.

Step 1. Determine the minimum and maximum speed balance points, $t_{3}$, and $t_{4}$.

$$
\begin{aligned}
& t_{3}=\frac{975 \cdot 0.77 \cdot 25000+47 \cdot(65-5)(13274-10355)-15 \cdot 10355 \cdot(65-5)}{15 \cdot 0.77 \cdot 25000+(65-5)(13274-10355)} \\
& t_{3}=38.11^{\circ} \mathrm{F} \\
& t_{4}=\frac{1950 \cdot 0.77 \cdot 25000+17(65-5)(30838-17112)-30 \cdot 17112 \cdot(65-5)}{30 \cdot 0.77 \cdot 25000+(65-5)(30838-17112)} \\
& t_{4}=14.80^{\circ} \mathrm{F} \quad(\text { eq. }(4.12)) \\
& \text { (4.13)) }
\end{aligned}
$$

Since calculated $t_{4}$ is smaller than 17 , the applied equation is the right one. If obtained value were greater than 17, equation (4.14) would be used.

Since $t_{4}<t_{j}=27<t_{3}$ we have Case II.

Step 2. Evaluate $t_{\mathrm{vh}}$.

$$
\begin{aligned}
& Q^{\mathrm{k}=1}(35)=10355+(13274-10355)(35-47) / 15=8019.8 \mathrm{Btu} / \mathrm{h} \quad(\text { eq. }(4.15)) \\
& \mathrm{N}_{\mathrm{Q}}=(10233-8019.8) /(22930-8019.8)=0.14844 \\
& \mathrm{M}_{\mathrm{Q}}=(13274-10355)(1-0.14844) / 15+(22930-17112) \cdot 0.14844 / 18=213.69 \\
& (\mathrm{eq} \cdot(4.21))
\end{aligned}
$$


$t_{v h}=\frac{65 \cdot 0.77 \cdot 25000+(65-5)(35 \cdot 213.69-10233)}{0.77 \cdot 25000+213.69 \cdot(65-5)}=33.86^{\circ} \mathrm{F} \quad(\mathrm{eq} \cdot(4.23))$

Step 3. Calculate power at temperature $t_{\mathrm{vh}}$

$$
\begin{aligned}
& \mathrm{E}^{\mathrm{k}=1}(35)=960+(1101-960)(35-47) / 15=847.2 \mathrm{~W} \quad(\text { eq. }(4.16)) \\
& N_{E}=(1106-847.2) /(2900-847.2)=0.12607 \quad(\text { eq. }(4.26)) \\
& M_{E}=(1101-960)(1-0.12607) / 15+(2900-2544) \cdot 0.12607 / 18=10.708 \\
& \text { (eq. }(4.25)) \\
& E_{d e f}^{k=1}(33.86)=1106+10.708 \cdot(33.86-35)=1093.8 \mathrm{~W} \quad(\text { eq. }(4.24))
\end{aligned}
$$

Step 4. Calculate COP at temperature $t_{3}=38.11, t_{v h}=33.86$, and $t_{4}=14.8$.

$$
\begin{aligned}
& \mathrm{Q}^{\mathrm{k}=1}(38.11)=\mathrm{BL}(38.11)=(65-38.11) \cdot 0.77 \cdot 25000 /(65-5)= \\
& \begin{array}{l}
8627.2 \mathrm{Btu} / \mathrm{h} \\
(\text { eq. } \cdot(4.4))
\end{array} \\
& \mathrm{E}^{\mathrm{k}=1}(38.11)=960+(1101-960)(38.11-47) / 15=876.4 \mathrm{~W} \quad(\text { eq. }(4.16))
\end{aligned}
$$

$$
\operatorname{COP}^{k=1}(38.11)=\frac{8625.0}{3.413 \cdot 876.4}=2.883 \quad(\text { eq. }(4.28))
$$$$
\mathrm{Q}_{\mathrm{def}}^{\mathrm{k}=1}(33.86)=\mathrm{BL}(33.86)=(65-33.86) \cdot 0.77 \cdot 25000 /(65-5)=9990.8 \mathrm{Btu} / \mathrm{h}
$$$$
\text { (eq. }(4.4))
$$

$$
\operatorname{COP}_{\mathrm{d} \text { ef }}^{\mathrm{k}}=\mathrm{i}(33.86)=\frac{9990.8}{3.413 \cdot 1093.8}=2.676 \quad(\text { eq. }(4.27))
$$$$
\mathrm{Q}^{\mathrm{k}=2}(14.80)=\mathrm{BL}(14.80)=(65-14.80) \cdot 0.77 \cdot 25000 /(65-5)=16105.8 \mathrm{Btu} / \mathrm{h}
$$$$
\text { (eq. }(4.4) \text { ) }
$$$$
\mathrm{E}^{\mathrm{k}=2}(14.80)=2544+(3236-2544)(14.80-17) / 30=2493.3 \mathrm{~W} \quad(\text { eq. }(4.37))
$$

(If $t_{4}$ were greater than 17 , equation (4.35) would be used) 


$$
\operatorname{COP}^{\mathrm{k}=2}(14.80)=\frac{16105.8}{3.413 \cdot 2493.3}=1.893
$$

Step 5. Evaluate parameters for a parabolic fit.

$$
\begin{aligned}
& d=\left(38.11^{2}-14.80^{2}\right) /\left(33.86^{2}-14.80^{2}\right)=1.3298 \quad(\text { eq. }(4.30)) \\
& b=\frac{1.893-2.883-1.3298 \cdot(1.893-2.676)}{14.80-38.11-1.3298 \cdot(14.80-33.86)}=2.5164 \cdot 10^{-2} \quad(\text { eq. }(4.31)) \\
& c=\frac{1.893-2.883-2.5164 \cdot 10^{-2} \cdot(14.80-38.11)}{14.80^{2}-38.11^{2}}=3.2711 \cdot 10^{-4} \quad(\text { eq. }(4.32)) \\
& a=1.893-2.5164 \cdot 10^{-2} \cdot 14.8-3.2711 \cdot 10^{-4} \cdot 14.8^{2}=1.4489 \\
& \text { (eq. }(4.33)) \\
& \mathrm{Q}(27)=\mathrm{BL}(27)=(65-27) \cdot 0.77 \cdot 25000 /(65-5)=12191.7 \mathrm{Btu} / \mathrm{h} \\
& \text { (eq. }(4.4)) \\
& \operatorname{COP}^{\mathrm{k}=\mathrm{v}}(27)=1.4489+2.5164 \cdot 10^{-2} \cdot 27+3.2711 \cdot 10^{-4} \cdot 27^{2}=2.367 \\
& E(27)=12191.7 /(3.413 \cdot 2.367)=1509.1 \mathrm{~W} \quad \text { (eq. (4.18)) }
\end{aligned}
$$

Step 7. Calculate seasonally weighted capacity, the energy input to the heat pump, and energy input to the electric heater.

$$
\begin{aligned}
& \mathrm{BL}(27)=(65-27) \cdot 0.77 \cdot 25000 /(65-5)=12191.7 \quad \mathrm{Btu} / \mathrm{h} \\
& \mathrm{n}_{8}=0.087 \\
& \mathrm{n}_{8} \cdot \mathrm{BL}(27)=0.087 \cdot 12191.7=1060.7 \mathrm{Btu} / \mathrm{h} \\
& \delta(27)=1
\end{aligned}
$$


$\mathrm{n}_{8} \cdot \mathrm{RH}(27)=0$

It should be noted that calculations steps related to evaluation of the minimum and maximum speed balance points, and evaluation of coefficients for the parabolic fit of $\mathrm{COP}$ in the intermediate speed range (Steps 1 through 5) have to be performed one time for each design heating requirement and climate region for which seasonal performance of a heat pump is evaluated. Once the parabolic fit is determined for a given region and DHR, calculations for succeeding temperature bins in the intermediate speed range include only steps 6 and 7 . 


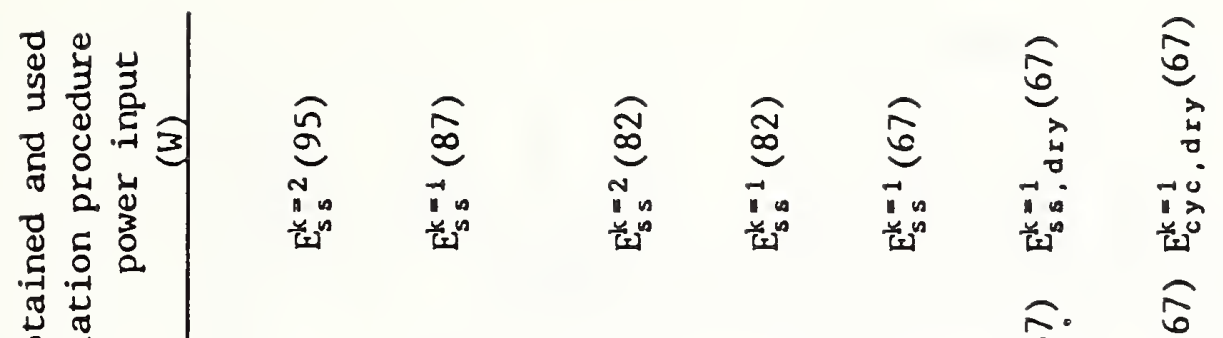

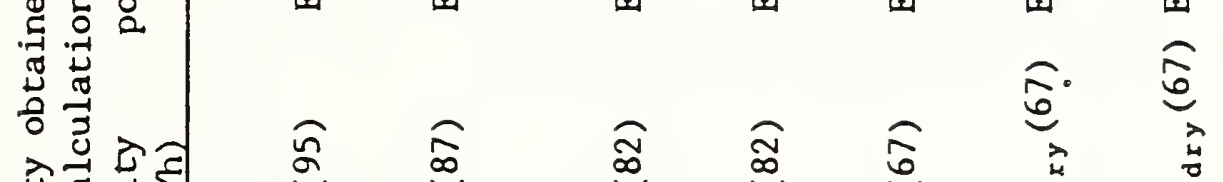

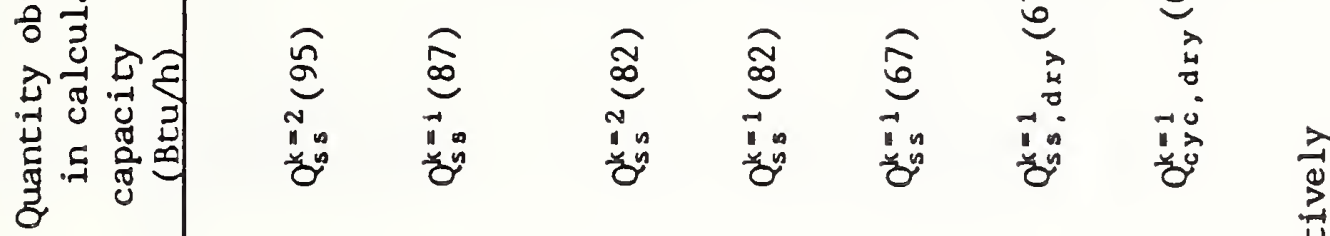

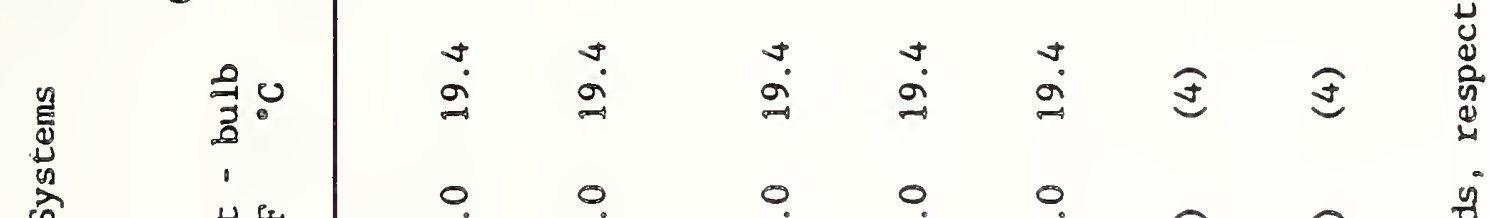

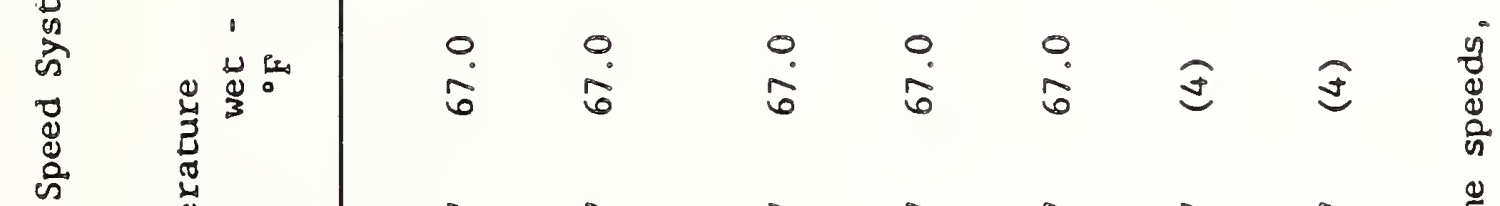

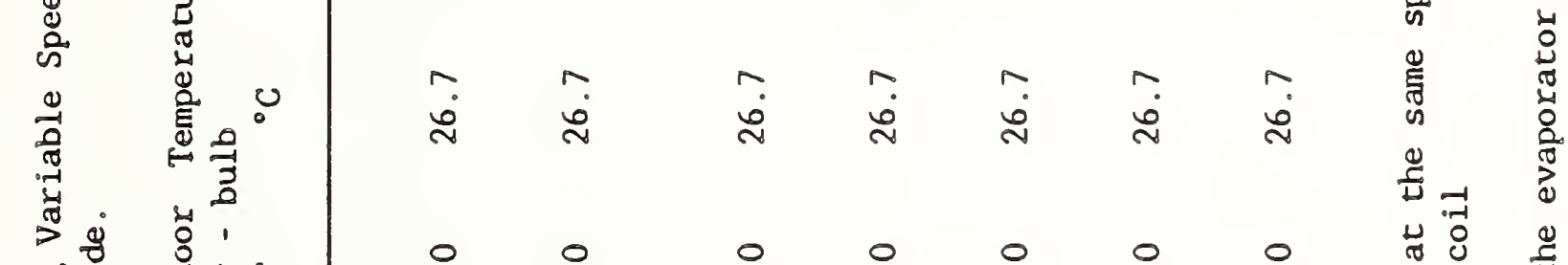

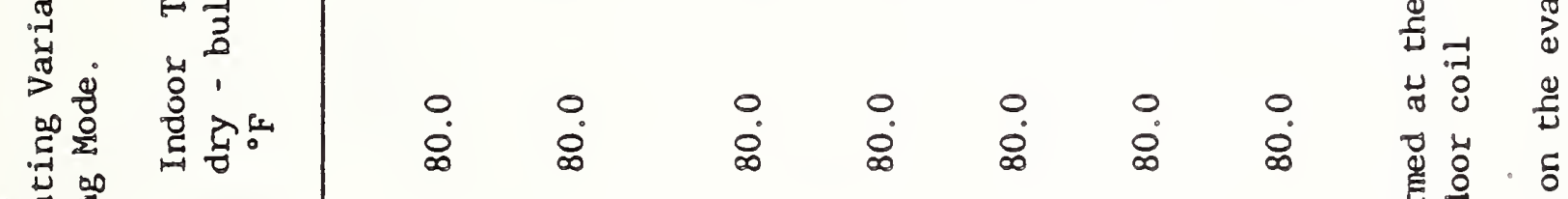

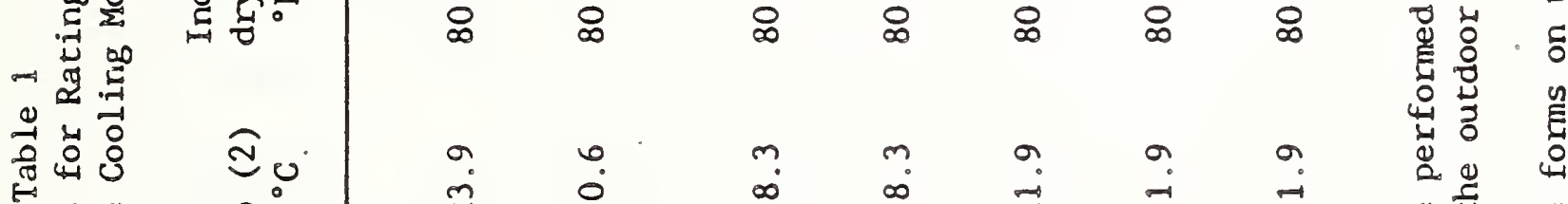

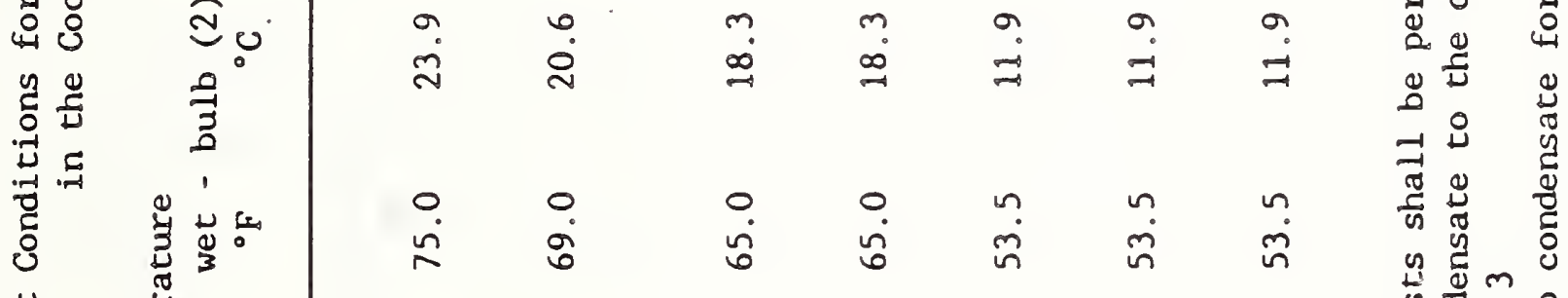

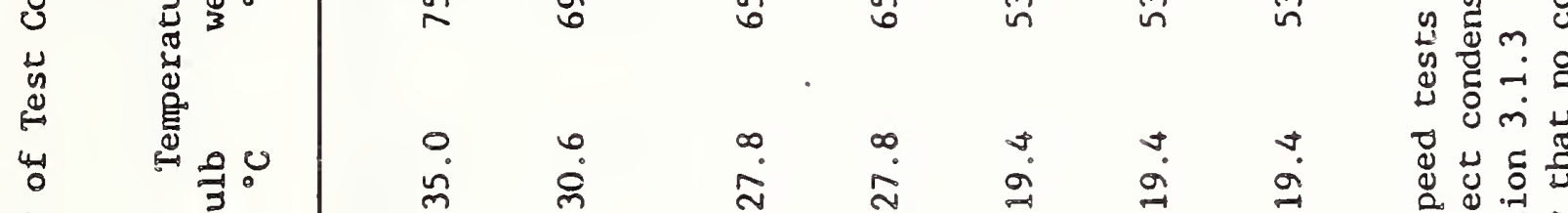

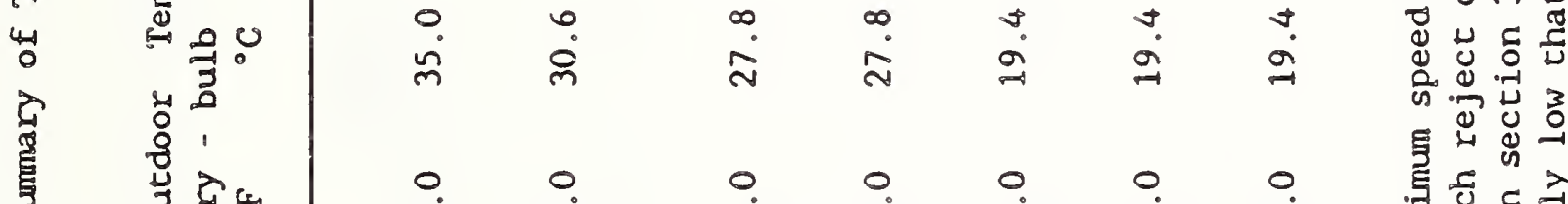

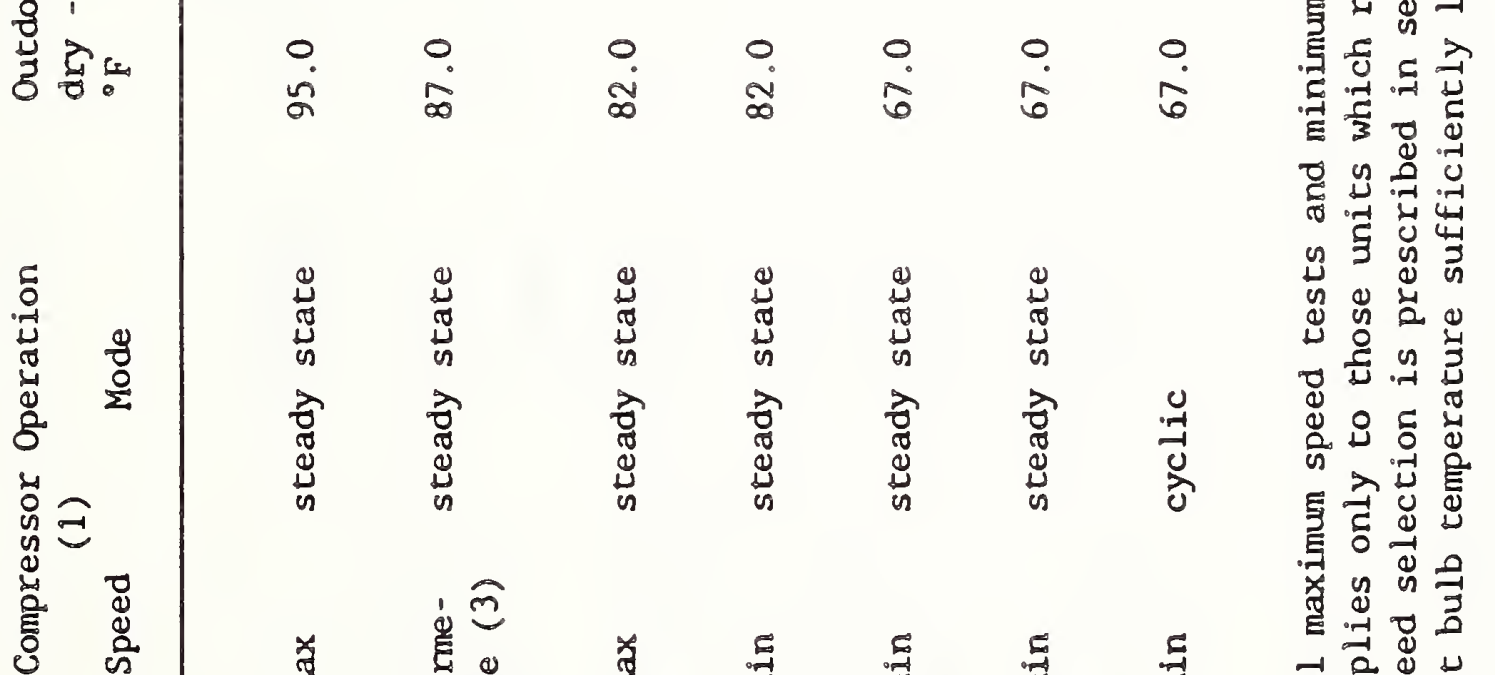

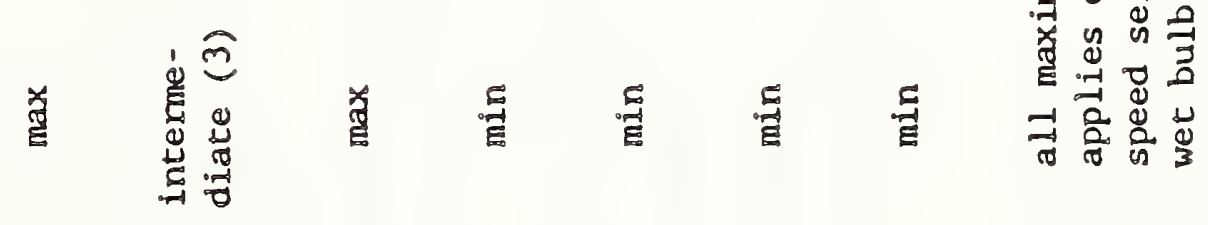

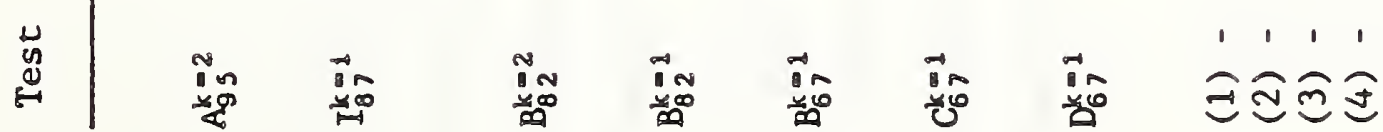


Table 2.

Distribution of Fractional Hours in Temperature Bins to be Used for Calculation of SEER.

$\begin{array}{ccc}\begin{array}{c}\text { Bin } \\ \text { number } \\ j\end{array} & \begin{array}{c}\text { Bin } \\ \text { temperature } \\ t_{j}\left({ }^{\circ} \mathrm{F}\right)\end{array} & \begin{array}{c}\text { Fraction of total } \\ \text { temperature bin hours } \\ n_{j}\end{array} \\ 1 & 67 & 0.214 \\ 2 & 72 & 0.231 \\ 4 & 77 & 0.216 \\ 5 & 82 & 0.161 \\ 6 & 87 & 0.104 \\ 7 & 92 & 0.052 \\ 8 & 97 & 0.018\end{array}$




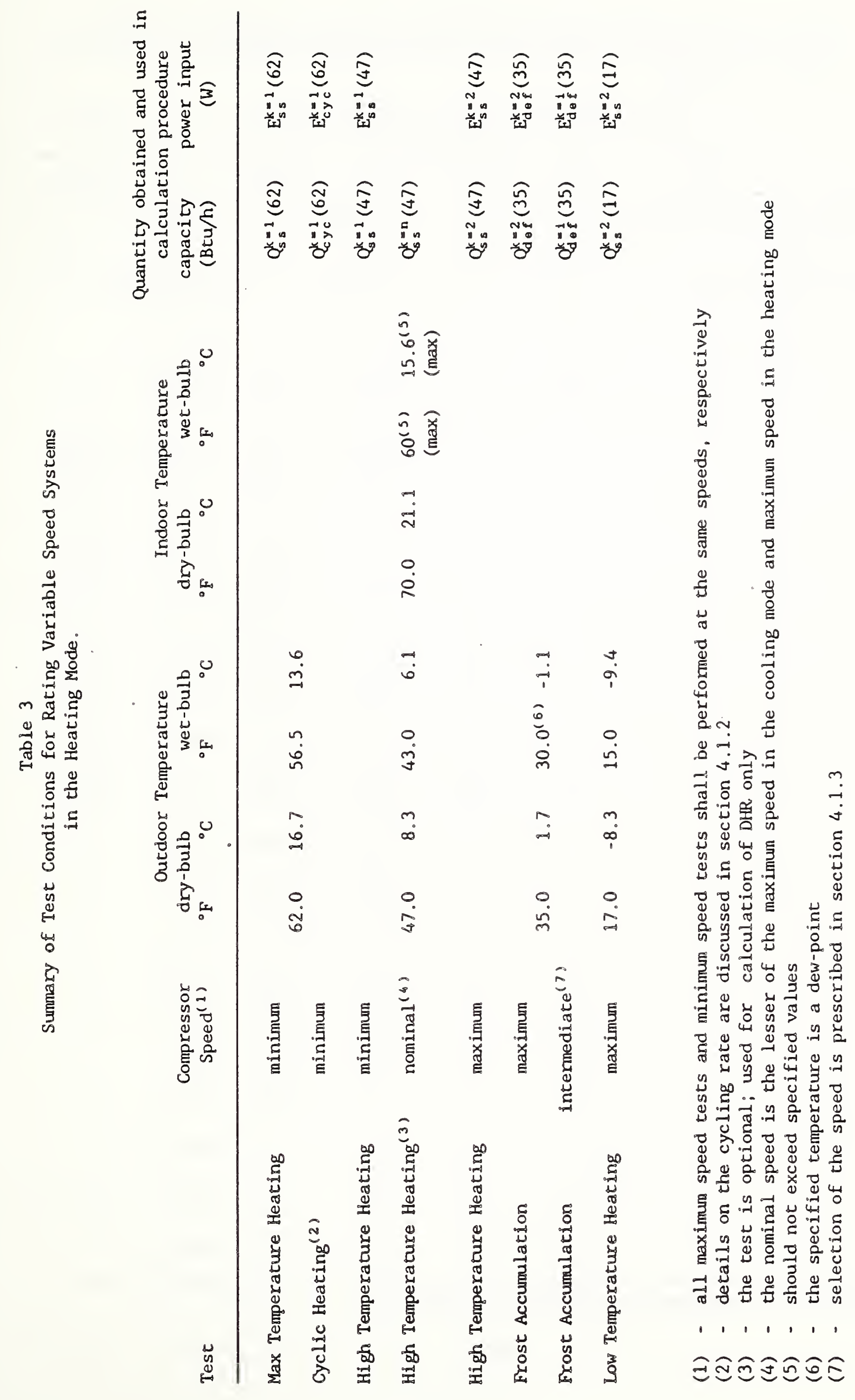


Table 4. Distribution of Fractional Heating Hours in Temperature Bins, Heating Load Hours and Outdoor Design Temperature for Different Climate Regions.

\begin{tabular}{lcccccc}
\hline Region* & I & II & III & IV & V & VI \\
\hline Heating Load Hours, HLH & 750 & 1250 & 1750 & 2250 & 2750 & 2750 \\
\hline $\begin{array}{l}\text { Outdoor Design Temperature, } \\
\mathrm{T}_{\mathrm{D} \text { for the region }}\end{array}$ & 37 & 27 & 17 & 5 & -10 & 30 \\
\hline
\end{tabular}

Fractional Hours:

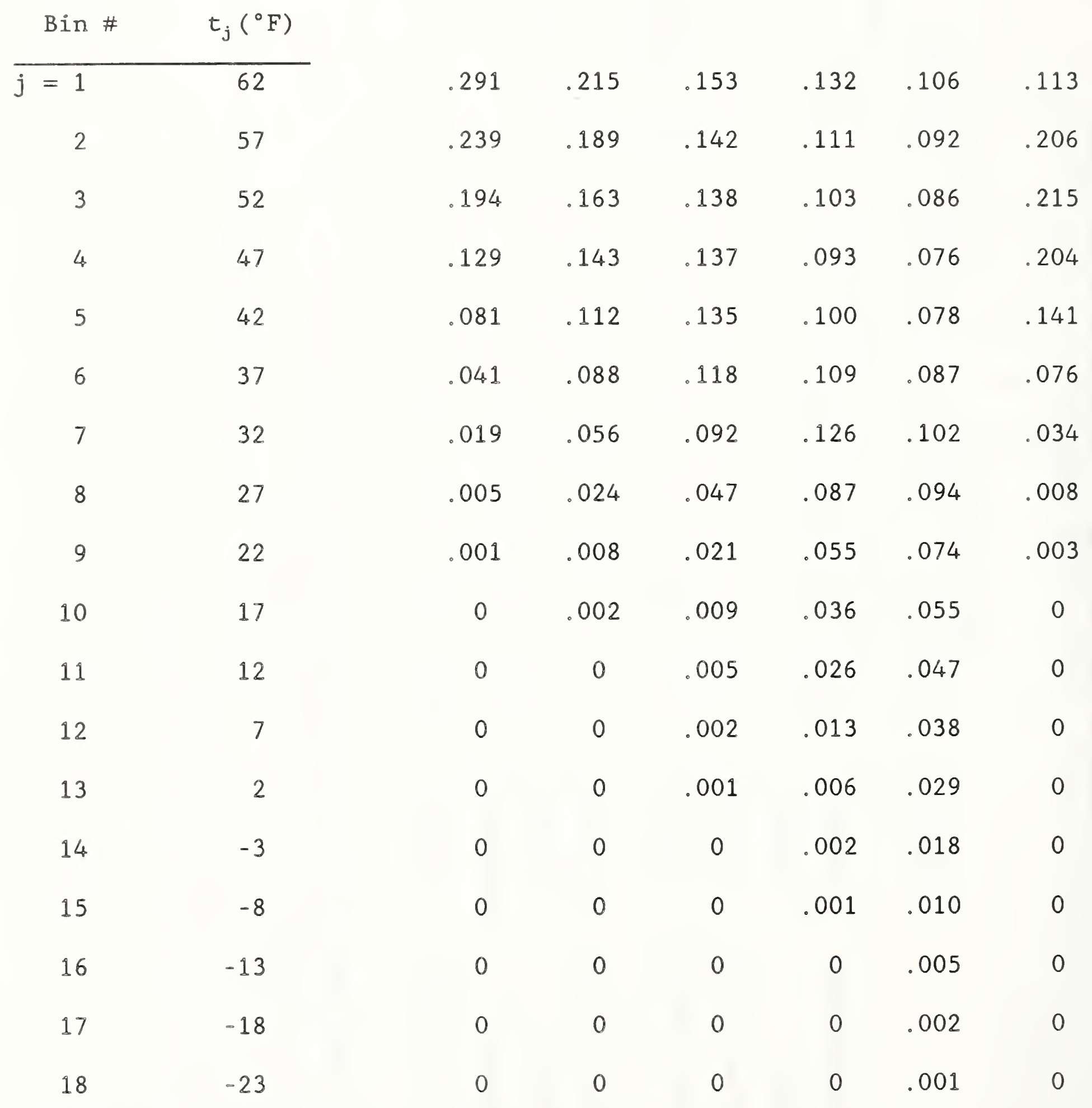

*Heating domestic regions are shown in Figure 11. 
Table 5

Standard Design Heating Requirements

(Btu/h)

$\begin{array}{llll}5,000 & 25,000 & 50,000 & 90,000 \\ 10,000 & 30,000 & 60,000 & 100,000 \\ 15,000 & 35,000 & 70,000 & 110,000 \\ 20,000 & 40,000 & 80,000 & 130,000\end{array}$


Table A1. Bin Calculation Worksheet for Evaluation of SEER.

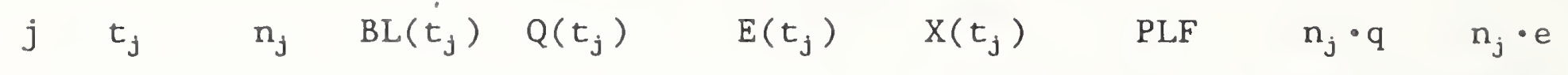

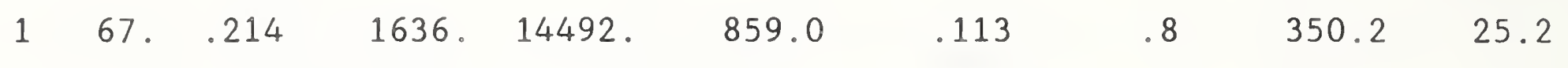
$\begin{array}{llllllllll}2 & 72 . & .231 & 5727 & 14038 & 892.0 & .408 & .9 & 1323.0 & 95.4\end{array}$

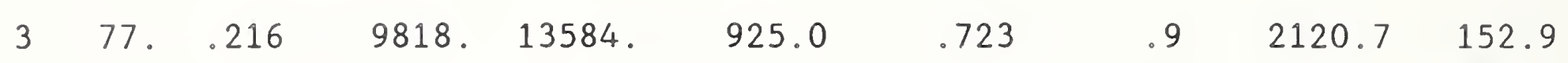

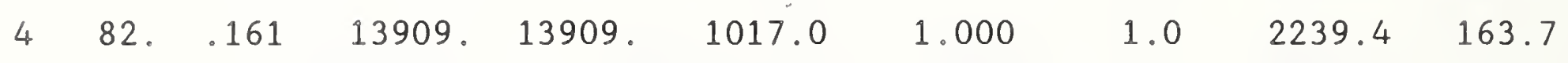

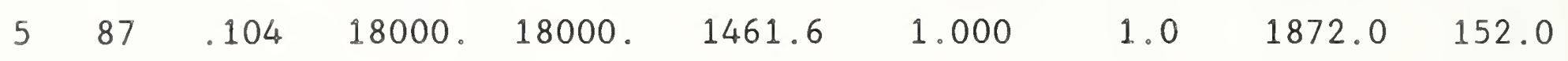
$\begin{array}{lllllllll}6 & 92 & 052 & 22091.22091 .2096 .7 & 1.000 & 1.0 & 1148.7 & 109.0\end{array}$

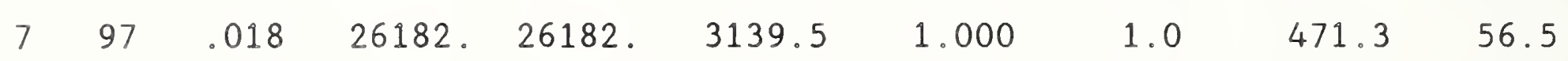

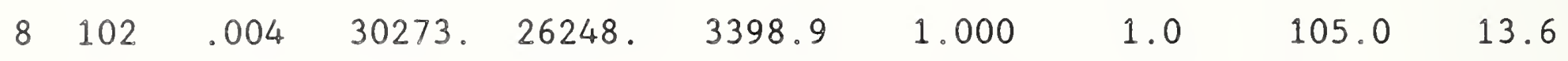
TOTALS: $\quad 9630.3 \quad 768.3$

$\operatorname{SEER}(B t u /(W \cdot h))=9630.3 / 768.3=12.53$ 
Table B1. Bin Calculation Worksheet for Evaluation of HSPF.

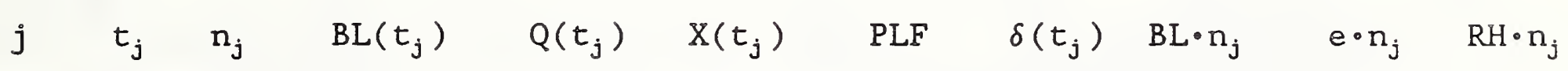

$\begin{array}{lllllllllll}1 & 62 . & .132 & 963 . & 13274 & .073 & .768 & 1.0 & 127.0 & 13.7 & .0\end{array}$

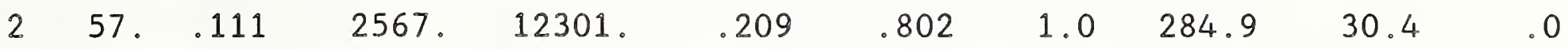

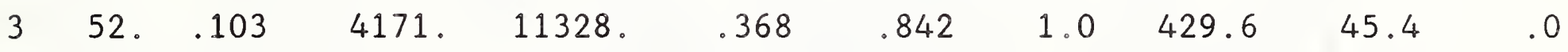

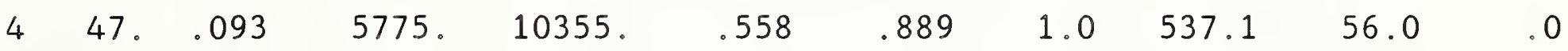

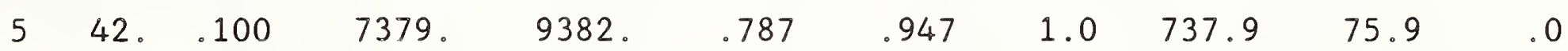

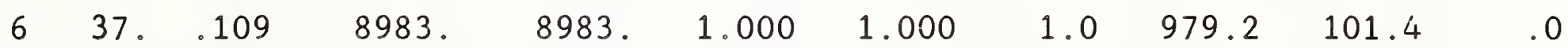

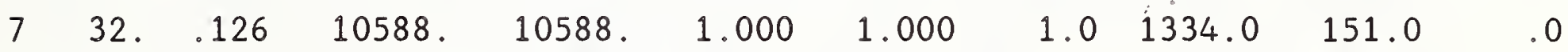

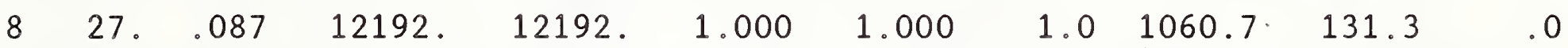
$\begin{array}{lllllllllll}9 & 22 . & .055 & 13796 . & 13796 . & 1.000 & 1.000 & 1.0 & 758.8 & 102.9 & .0\end{array}$

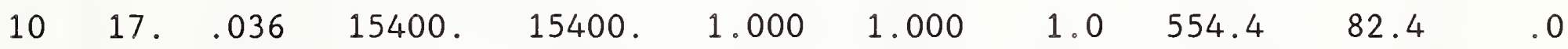

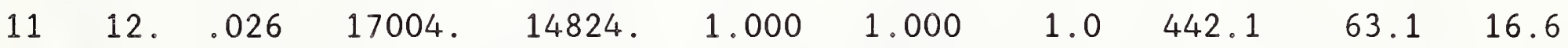

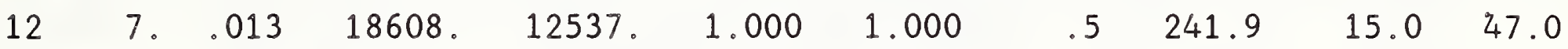

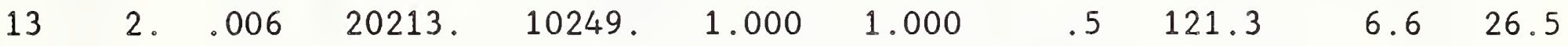

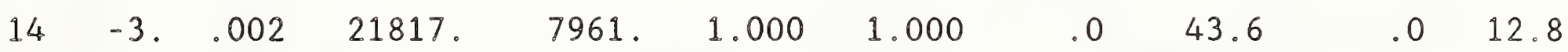

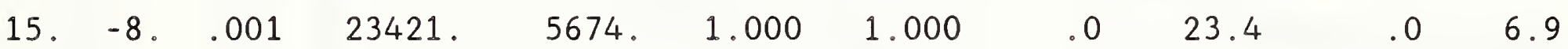

$\operatorname{HSPF}(B t u /(W \cdot h))=7675.9 /(875.2+109.8)=7.793$ 


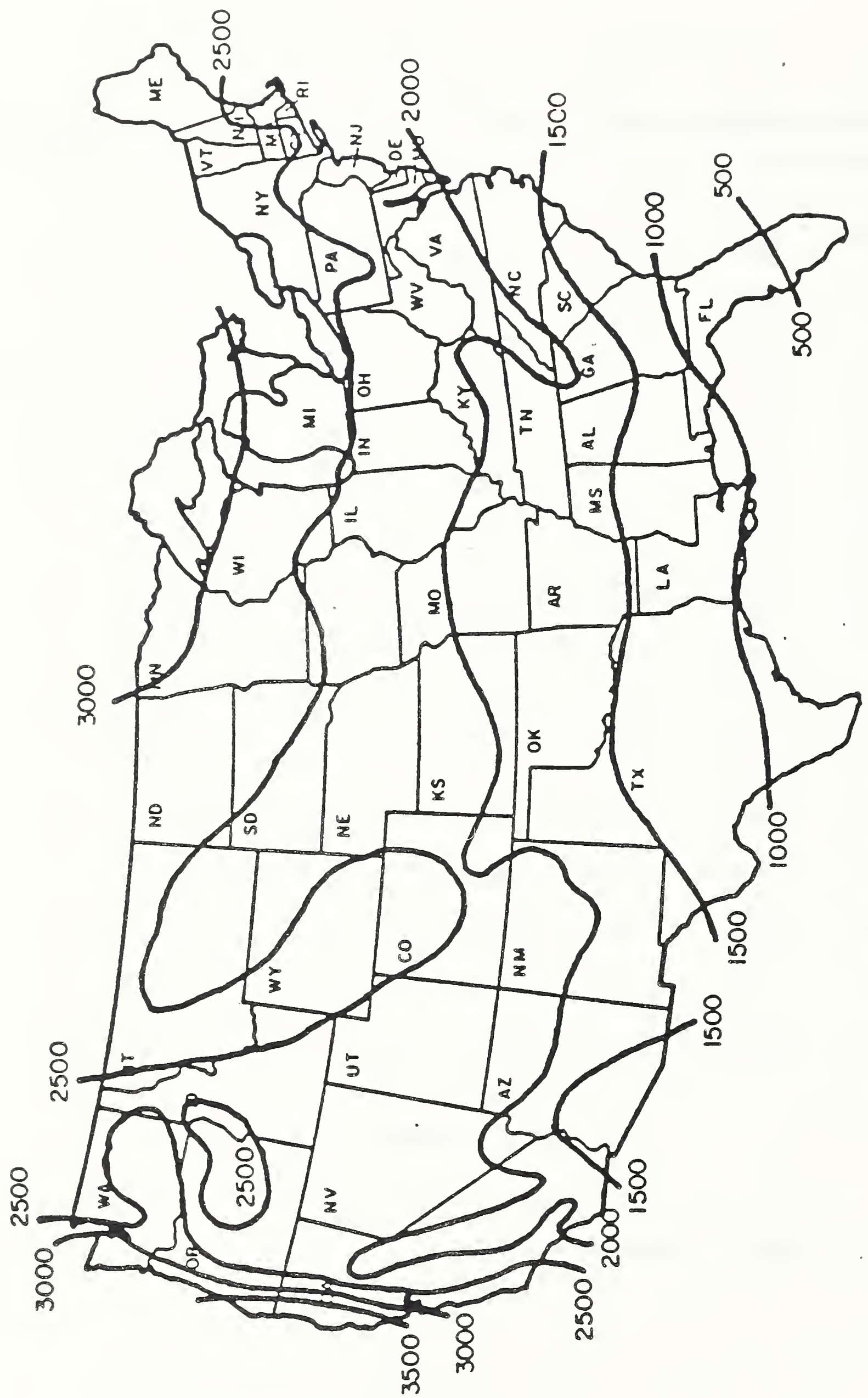




\section{NBS-114A (REV. 2.8C)}

U.S. DEPT. OF COMM.

BIBLIOGRAPHIC DATA

SHEET (See instructions)

1. PUBLICATION OR
REPORT NO.
NBSIR $88-3781$

2. Performing Organ. Report Noo 3. Publication Date

NBSIR 88-3781

MAY 1988

4. TITLE AND SUBTITLE

Recommended Procedure For Rating and Testing Of Variable Speed Air Source Unitary Air Conditioners And Heat Pumps

\section{5. $A \cup T H O R(S)$}

Piotr Domanski

6. PERFORMING ORGANIZATION (If joint or other than NBS. see instructions)

7. Contract/Grant No.

NATIONAL BUREAU OF STANDARDS

DEPARTMENT OF COMMERCE

WASHINGTON, D.C. 20234

8. Type of Report \& Period Covered

9. SPONSORING ORGANIZATION NAME AND COMPLETE ADDRESS (Street。City。 $\overline{\text { State }} \overline{\text { ZIP) }}$

DOE

Washington, DC 20585

10. SUPPLEMENTARY NOTES

Document describes a.computer program; SF-185, FIPS Software Summary, is attached.

11. ABSTRACT (A 200-word or less factual summary of most significant information. If document includes a significant bibliography or literature survey, mention it here)

A procedure is presented for testing and rating variable speed, split residential air conditioners and heat pumps. The procedure is derived in part from existing procedures for single speed and two speed systems where these procedures could be applied, and introduces a new algorithm for representation of variable speed unit performance in the intermediate speed operation range. Analysis and background which led to the formulation of the procedure are included as well as calculation examples for the cooling and heating mode. This procedure has been prepared for the Department of Energy for consideration in the rule making process.

13. KEY WORDS (Six to twelve entries: alphabetical order; capitalize only proper names; and separate key words by semicolons) air conditioner; central air conditioner; heat pump; rating procedure; variable speed system

13. AVAILABILITY

14. NO. OF

PRINTED PAGES

Unlimired

For Official Distribution. Do Not Release to NTIS

Order From Superintendent of Documents, U.S. Government Printing Office, Washington, D.C. 20402.

X. Order From National Technical Information Service (NTIS), Springfield, VA. 22161

\section{0}

15. Price

$\$ 13.95$ 
